\title{
Prediction of Topsoil Organic Carbon Using Airborne and Satellite Hyperspectral Imagery
}

\author{
Juanjo Peón ${ }^{1, *}$ (D), Carmen Recondo ${ }^{1,2}$ (D) , Susana Fernández ${ }^{3,4}$, Javier F. Calleja ${ }^{5}$ (i), \\ Eduardo De Miguel ${ }^{6}$ and Laura Carretero ${ }^{6}$ \\ 1 Remote Sensing Applications Research Group (RSApps), Area of Cartographic, Geodesic and \\ Photogrammetric Engineering, Department of Mining Exploitation and Prospecting, University of Oviedo, \\ Gonzalo Gutiérrez Quirós s/n, 33600 Mieres, Asturias, Spain; mdrecondo@uniovi.es \\ 2 Institute of Natural Resources and Territorial Planning (INDUROT), University of Oviedo, Gonzalo \\ Gutiérrez Quirós s/n, 33600 Mieres, Asturias, Spain \\ 3 Department of Geology, University of Oviedo, Jesús Arias de Velasco s/n, 33005 Oviedo, Asturias, Spain; \\ fernandezmsusana@uniovi.es \\ 4 GIS-Forest Group, Department of Organisms and Systems Biology, University of Oviedo, Gonzalo Gutiérrez \\ Quirós s/n, 33600 Mieres, Asturias, Spain \\ 5 Remote Sensing Applications Research Group (RSApps), Department of Physics, Polytechnic School of \\ Mieres, University of Oviedo, Gonzalo Gutiérrez Quirós s/n, 33600 Mieres, Asturias, Spain; \\ jfcalleja@uniovi.es \\ 6 National Institute for Aerospace Technology (INTA), Carretera Torrejón a Ajalvir, $\mathrm{km} \mathrm{4,}$ \\ 28850 Torrejón de Ardoz, Madrid, Spain; demiguel@inta.es (E.D.M.); carreteroml@inta.es (L.C.) \\ * Correspondence: juanjopeon@gmail.com; Tel.: +34-985-458011
}

Received: 25 July 2017; Accepted: 21 November 2017; Published: 24 November 2017

\begin{abstract}
The Airborne Hyperspectral Scanner (AHS) and the Hyperion satellite hyperspectral sensors were evaluated for their ability to predict topsoil organic carbon (C) in burned mountain areas of northwestern Spain slightly covered by heather vegetation. Predictive models that estimated total organic $\mathrm{C}$ (TOC) and oxidizable organic $\mathrm{C}$ (OC) content were calibrated using two datasets: a ground observation dataset with 39 topsoil samples collected in the field (for models built using AHS data), and a dataset with 200 TOC/OC observations predicted by AHS (for models built using Hyperion data). For both datasets, the prediction was performed by stepwise multiple linear regression (SMLR) using reflectances and spectral indices (SI) obtained from the images, and by the widely-used partial least squares regression (PLSR) method. SMLR provided a performance comparable to or even better than PLSR, while using a lower number of channels. SMLR models for the AHS were based on a maximum of eight indices, and showed a coefficient of determination in the leave-one-out cross-validation $\mathrm{R}^{2}=0.60-0.62$, while models for the Hyperion sensor showed $\mathrm{R}^{2}=0.49-0.61$, using a maximum of 20 indices. Although slightly worse models were obtained for the Hyperion sensor, which was attributed to its lower signal-to-noise ratio (SNR), the prediction of TOC/OC was consistent across both sensors. The relevant wavelengths for TOC/OC predictions were the red region of the spectrum $(600-700 \mathrm{~nm})$, and the short wave infrared region between $\sim 2000-2250 \mathrm{~nm}$. The use of SMLR and spectral indices based on reference channels at $1000 \mathrm{~nm}$ was suitable to quantify topsoil C, and provided an alternative to the more complex PLSR method.
\end{abstract}

Keywords: topsoil organic carbon mapping; imaging spectroscopy; AHS; Hyperion; spectral indices

\section{Introduction}

Soil organic carbon (SOC) is one of the Earth's main carbon (C) reservoirs, with a predicted amount greater than $1500 \mathrm{Pg} \mathrm{C}$ to 1-m depth [1,2]. Small changes in the SOC pool could have a 
significant impact on the atmospheric $\mathrm{CO}_{2}$ concentration and affect the climate [3]. The measurement of these pools at the range of spatial and temporal scales still remains a challenge [4]. Rapid and accurate methods are needed for improving the inventory, spatial distribution, and temporal dynamics of SOC $[5,6]$.

Conventional methods for mapping SOC stocks involve the collection and analysis of point soil samples, calibration of a spatial prediction function, and interpolation of the function over the whole study area [7]. These methods are expensive and time-consuming because of the large number of samples required to capture the high spatial variability of SOC [8].

Laboratory-based measurements of soil C using standard methods, such as dry combustion [9] and the Walkley-Black method [10], also involves intensive and costly procedures. Soil diffuse reflectance spectroscopy in the visible (VIS, 400-700 nm), near infrared (NIR, 700-1300 nm), and short-wave infrared (SWIR, 1300-2500 nm) has been demonstrated to be an alternative to traditional methods for SOC prediction. Currently, lab spectroscopy is well established as an accurate, rapid, and non-destructive technique to predict a wide range of soil properties [11], including organic C [12-15] and total C [16-18].

Lab spectroscopy can be extended to a regional scale using airborne and satellite hyperspectral sensors. However, the use of hyperspectral sensors at a remote sensing scale has several limitations, such as atmospheric absorptions, illumination variations, the low signal-to-noise ratios of the sensors, and spectral mixing $[19,20]$. Due to these limitations, relatively few studies have used data from airborne and satellite hyperspectral sensors to estimate SOC and organic matter, either at the within-field scale or at the regional scale. Several hyperspectral airborne sensors were tested to predict SOC and organic matter over agricultural fields or semi-arid areas, including HyMap [21-26], Airborne Hyperspectral Scanner (AHS) [8,27-30], Compact Airborne Spectrographic Imager (CASI) [31,32], Airborne Visible and Near-Infrared (AVNIR) [33], DAIS-7915 [34], and HyperSpecTIR [35]. However, very few studies used airborne hyperspectral data to estimate SOC and organic matter over areas partially covered by vegetation, in either agricultural areas [36,37] or burned areas with a partial vegetation cover resulting from post-fire regeneration [38]. Satellite hyperspectral data was seldom used to estimate SOC, and only one satellite sensor, Hyperion, was used to predict SOC and organic matter over agricultural fields and bare soils [39-41]. Hyperion data was also used to estimate SOC and organic matter over maize crops [42], and over forests, pastures, and agricultural fields with inaccurate results [43].

The prediction of SOC using spectroscopy is usually based on several multivariate statistical techniques or data mining algorithms, such as multiple linear regression, stepwise multiple linear regression [44,45], principal component regression [46,47], regression trees [48], support vector machine regression [18], and artificial neural networks [49]. Partial least squares regression (PLSR) is one the most widely-used techniques, mainly because it handles multicollinearity in the reflectance spectra, and it is robust in terms of data noise [11]. However, an important drawback is that PLSR does not provide a quantitative explanation for the relationship between predictor variables and response variables [50], and it is complex to transfer models from one sensor to another [51]. Linear regression methods using spectral indices are less sophisticated than PLSR, easier to transfer among sensors, and based on the physical analysis of spectral reflectance, so they are used as an alternative modeling method to PLSR [50,51].

So far, the estimation of SOC using airborne and satellite hyperspectral sensors was mainly restricted to small agricultural or bare soil areas, and it still remains in the testing phases. Furthermore, the calibration technique used for SOC prediction in most of the previous studies was the PLSR method, which has several drawbacks related to the physical interpretation of the results and the complexity of transferring the models from one sensor to another.

The aim of this work was to assess the capability of two hyperspectral sensors, the Airborne Hyperspectral Scanner (AHS) and the Hyperion satellite hyperspectral sensor, to estimate SOC in burned mountain areas that are slightly covered by vegetation as a result of post-fire regeneration. 
The SOC estimation was carried out using simple and multiple linear regression techniques based on image reflectance values and spectral indices (SI), which are less sophisticated than the widely-used PLSR method, and have greater potential to be transferred among sensors. Comparison of prediction performance with PLSR results allowed us to evaluate whether the proposed regression models provide an acceptable accuracy.

\section{Materials and Methods}

\subsection{Study Area}

The study area is located on the western side of the Cantabrian Range (NW of Spain), and consists of a NW-SE rectangle of approximately $60 \mathrm{~km}^{2}$, which corresponds to the AHS image extent (Figure 1). The area corresponds to a mountain region with an altitude range from 400 to $1700 \mathrm{~m}$ above sea level, and an average slope of $\sim 25^{\circ}$. The climate is Atlantic, with an average annual air temperature of $8{ }^{\circ} \mathrm{C}$ and an average annual precipitation of $1500 \mathrm{~mm}$. The bedrock is very homogeneous, and is mainly composed of quartzite, sandstone, and slate. The soils are classified as Lithosols, Histosols, and Regosols, according to the World Reference Base [52], and are sandy, shallow, and stony. We chose this region because it has been affected by frequent wildfires [53], and soil in this area contains high amounts of organic matter [54], which makes it well-suited for the study. As a result of the degradation caused by the repeated burning of this region, the landscape is dominated by extensive areas of heath formations, and deciduous forests, to a lesser extent [55]. The abundance of heaths within the burned slopes located in the study area varies along a N-S gradient, with higher abundance in the northern areas. The wildfire incidence map obtained with Landsat [56] data showed regions of the study area affected by up to four wildfires from 1984 to 2011. The last wildfires in the study area were recorded in 2005 (center of the study area), 2006 (south), and 2011 (north and center-south).

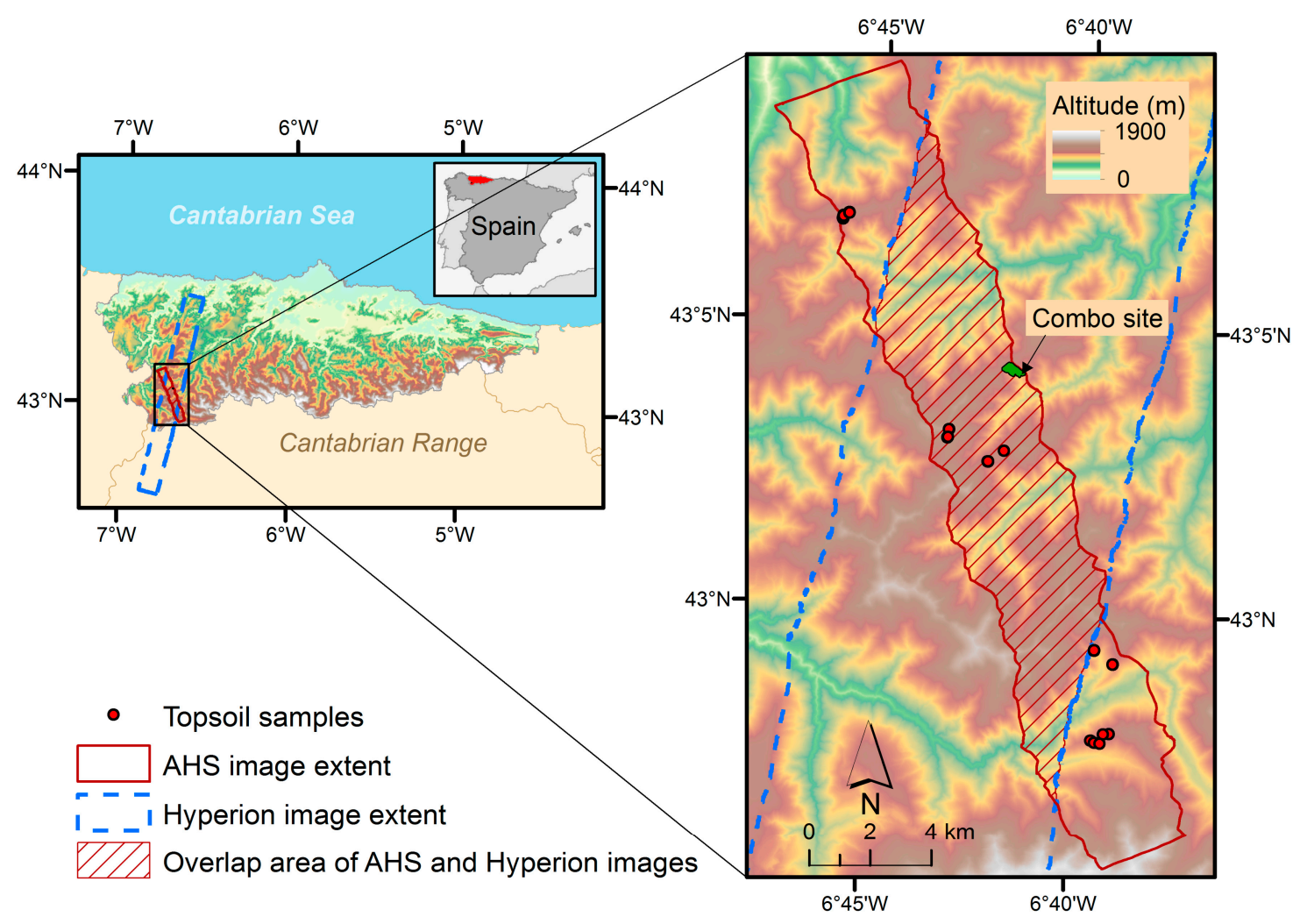

Figure 1. Location of the study area in NW Spain and extent of the Airborne Hyperspectral Scanner (AHS) and Hyperion images. 


\subsection{Airborne Hyperspectral Data}

A hyperspectral image was acquired over the study area by an Airborne Hyperspectral Scanner (AHS) mounted on a CASA 212-200 airplane (Figure 1). The image was collected on 10 October 2011 at 11:05 UTC, in a flight campaign conducted by the Spanish National Institute for Aerospace Technology (INTA). Weather conditions were favorable during the flight, with clear sky and light wind from the east. The AHS is a whiskbroom line scanner with a field of view (FOV) of $90^{\circ}$ and 750 pixels in the across-track direction. The instantaneous FOV (IFOV) is $2.5 \mathrm{mrad}$, which results in a spatial resolution of $5 \mathrm{~m}$ for a flight height of $\sim 1860 \mathrm{~m}$ above ground level. The AHS sensor has 80 channels from 443 to $12,952 \mathrm{~nm}$. In this paper, only 63 channels in the reflective part of the electromagnetic spectrum were used: 20 channels between 443-1001 nm (VIS-NIR), with a full width at half maximum (FWHM) of 27-29 nm, and a mean signal-to-noise ratio (SNR) of 473:1, 1 channel at $1590 \mathrm{~nm}$ (SWIR) with a FWHM of $85 \mathrm{~nm}$ and a SNR of 207:1, and 42 between 1924-2553 nm (SWIR) with a FWHM of 14-18 nm and a mean SNR of 18:1.

The AHS image was geometrically and radiometrically corrected by INTA. The geometric correction was performed using the direct georeferencing code PARGE [57], and a 5-m resolution digital elevation model (DEM) provided by the Spanish National Geographic Institute (IGN). Data were projected to Universal Transverse Mercator (UTM), World Geodetic System (WGS) 84 datum and zone $30 \mathrm{~N}$. The image was atmospherically and topographically corrected using ATCOR4 [58] to obtain the hemispherical-directional reflectance factor (HDRF). Spectral channels with a low SNR (SNR <10) and those located at wavelengths with strong atmospheric water vapor absorption were removed. Consequently, work was carried out with 38 AHS channels, 19 in the VIS-NIR and 19 in the SWIR.

A pixel-based supervised classification was performed on the AHS image to distinguish the burned areas, as well as the other land cover classes in the scene. The following classes were used in a true-color composite of the AHS image (bands at 650,560 and $443 \mathrm{~nm}$ in the red, green and blue channels): rock, forest, herbaceous, and burned areas. This study comprises only the burned regions, which covered an area of $\sim 8 \mathrm{~km}^{2}$. A maximum likelihood classifier [59] was calibrated using a set of training sites located in the scene. The number of training sites of each class ranged between 13 and 21. A land cover map based on field data (scale 1:25,000) was used to determine the training sites. The overall accuracy of the classification was $93.5 \%$.

\subsection{Satellite Hyperspectral Data}

The Hyperion sensor on board the Earth Observing-1 (EO-1) satellite acquired a hyperspectral image of the study area on 30 September 2014 at 9:51 UTC, in response to a data acquisition request submitted using the National Aeronautics and Space Administration (NASA) experimental system SensorWeb. Hyperion has two pushbroom spectrometers, one in the VIS-NIR spectral region, and another in the SWIR spectral region. It collects 242 contiguous channels in the spectral range from $360 \mathrm{~nm}$ to $2580 \mathrm{~nm}$, with a FWHM of 10-12 nm and a spatial resolution of $30 \mathrm{~m}$. The Hyperion SNR decreases as the wavelength increases: $161: 1$ at $550 \mathrm{~nm}, 147: 1$ at $700 \mathrm{~nm}, 110: 1$ at $1125 \mathrm{~nm}$, and 40:1 at $2125 \mathrm{~nm}$ [60]. A FOV of $0.63^{\circ}$ at the EO- 1 orbit of $705 \mathrm{~km}$ achieves a $7.5-\mathrm{km}$ swath width. The $\sim 100-\mathrm{km}$ length Hyperion image of the study area (Figure 1) was downloaded at no cost from the United States Geological Survey (USGS) EarthExplorer platform. It was provided at a processing level 1T (L1T), with radiometric and geometric correction using ground control points, and georeferenced to the coordinate system UTM-WGS84-29N. The image was transformed to the coordinate system UTM-WGS84-30N. Channels that were not calibrated, located in strong atmospheric water vapor absorption regions, or in the overlapping region between both spectrometers, were removed. Unstable channels with a low SNR were also discarded. A total of 155 channels, which corresponded to the set of stable channels selected by Datt et al. [61], remained for further analysis.

Atmospheric/topographic correction and conversion of at-sensor radiance to surface reflectance was carried out using ATCOR4 [58], which is based on the MODTRAN5 radiative transfer code. A DEM with a spatial resolution of $5 \mathrm{~m}$ provided by IGN was resampled to the Hyperion resolution of 
$30 \mathrm{~m}$ and used for the illumination correction. The rural aerosol model was selected for the atmospheric correction. Visibility and water vapor maps were derived from the image. The water vapor retrieval was performed using the water absorption feature at $1130 \mathrm{~nm}$.

The image was also corrected for the bidirectional reflectance distribution function (BRDF) effects, which can be especially strong in rugged terrain zones similar to the study area. Several configurations of BRDF correction input parameters were tested in ATCOR4. The reflectance values obtained using the different configurations were compared with the reference reflectance values provided by a Moderate Resolution Imaging Spectroradiometer (MODIS) image, which was collected one hour and 20 min after the Hyperion acquisition time. We selected the MODIS surface reflectance product with the best spatial resolution, $250 \mathrm{~m}$ (MOD09GQ). The comparison between MODIS and Hyperion reflectance values corrected with the different configurations was carried out in 12 regions of the scene: six in slopes facing the sun, and six away from the sun. The BRDF corrected image, whose reflectance values were more similar to the MODIS values in these regions, was chosen as the best correction result. The best BRDF correction involved a separate treatment for non-vegetation and vegetation areas of the image.

After visual inspection of the corrected image, several channels were found to be affected by residual noise or light vertical striping. Noise and striping were reduced by using a principal component transformation [59]. This transformation was applied to convert the corrected image to a set of 155 linearly uncorrelated bands or principal components. The first principal components contained the largest amount of image variance, while the last components contained less information and more noise. An inverse rotation was applied to transform the principal components back into the original image space, but using only the first four components, which were not affected by noise, and contained $98.6 \%$ of the image variance. As a result, a 155-channel noise-reduced image was obtained and used for further analysis.

\subsection{Field Data}

Thirty-nine topsoil $(0-5 \mathrm{~cm})$ samples were taken in burned slopes in the summer of 2013 (Figure 1). In order to represent the $\mathrm{N}-\mathrm{S}$ gradient in the abundance of heaths, soil samples were taken in three regions located in the north, center, and south of the study area. The location of the sampling points was recorded by a handheld global positioning system (GPS) device with an accuracy of 3-5 $\mathrm{m}$ (95\% typical). The sampling strategy was designed originally for the 5-m resolution AHS image, and all of the samples were taken within the limits of this image in burned areas partially covered by heather. However, only 14 out of the 39 soil samples were located within limits of the Hyperion image, and only six were available if we consider that several 30-m Hyperion pixels contained more than one soil sample. Soil samples were air-dried, sieved $(<2 \mathrm{~mm})$, and homogenized in the lab. Total organic C (TOC) was analyzed by dry combustion at $950^{\circ} \mathrm{C}$ using a Vario C-N Analyzer (Elementar Analysensysteme GmbH, Langenselbold, Germany). In our study area, TOC is equivalent to total $C$, as the soil parent material is non-calcareous [54]. Oxidizable C (OC) was determined using the Walkley-Black method [10].

\subsection{Spectral Indices}

A wide range of spectral indices has been developed with the aim of estimating several biophysical parameters using remote sensing data [62]. The normalized difference vegetation index (NDVI) [63] is one of the most used vegetation indices because of its simplicity and effectiveness in quantifying green vegetation and discriminating different land covers. The NDVI is based on the reflectance measured in a red $\left(\varrho_{\text {red }}\right)$ and a NIR channel $\left(\varrho_{\text {NIR }}\right):$ NDVI $=\left(\varrho_{\text {NIR }}-\varrho_{\text {red }}\right) /\left(\varrho_{\text {NIR }}+\varrho_{\text {red }}\right)$. Due to its simple structure, it is easy to transfer this index among sensors. An important factor that allows the transfer of spectral indices between sensors is that these indices are relative values, and thus the differences in absolute reflectances between sensors are ruled out. After all, the reflectance is sensitive to the sensors' characteristics and atmospheric correction. Several biochemical constituents present in the vegetation and soil, such as chlorophyll, cellulose, and lignin, influence the reflectance in the VIS-NIR-SWIR regions [51,64]. These constituents are related to SOC [65], and several authors 
have identified wavelengths and spectral indices sensitive to SOC using lab and field VIS-NIR-SWIR reflectance spectra [51,66].

The most widely-used spectral indices are usually based on band differences, normalized differences, and band ratios. The normalized difference structure is well suited for vegetation studies [62] and was selected in this work, considering that the burned regions of the study area were partially covered by heather. The structure of the selected spectral index (SI) is the same as the NDVI: $\mathrm{SI}_{\lambda 2-\lambda 1}=\left(\varrho_{\lambda 2}-\varrho_{\lambda 1}\right) /\left(\varrho_{\lambda 2}+\varrho_{\lambda 1}\right)$, where $\varrho_{\lambda 1}$ and $\varrho_{\lambda 2}$ are the reflectance values at the effective $\left(\lambda_{1}\right)$ and reference $\left(\lambda_{2}\right)$ wavelengths. The values of this index range from -1 to 1 . Indices with this structure were calculated from the reflectance values of the AHS and Hyperion images, using all possible two-band combinations (1406 indices for AHS, and 23,870 for Hyperion).

\subsection{SOC Modelling Using Airborne Hyperspectral Data}

The overall process of SOC estimation (TOC and OC) is shown in the flowchart in Figure 2. Reflectances and spectral indices from the AHS images were extracted for the location of the 39 soil samples and related to the TOC and OC values obtained in the chemical analysis. Reflectances and spectral indices were correlated to TOC and OC values using simple linear regression (SLR). A correlogram showing the Pearson correlation coefficient (R) versus the wavelengths was generated for both soil properties in order to identify the best AHS channels for estimating TOC and OC. For the identification of the best spectral indices, two-dimensional (2-D) correlograms were created.

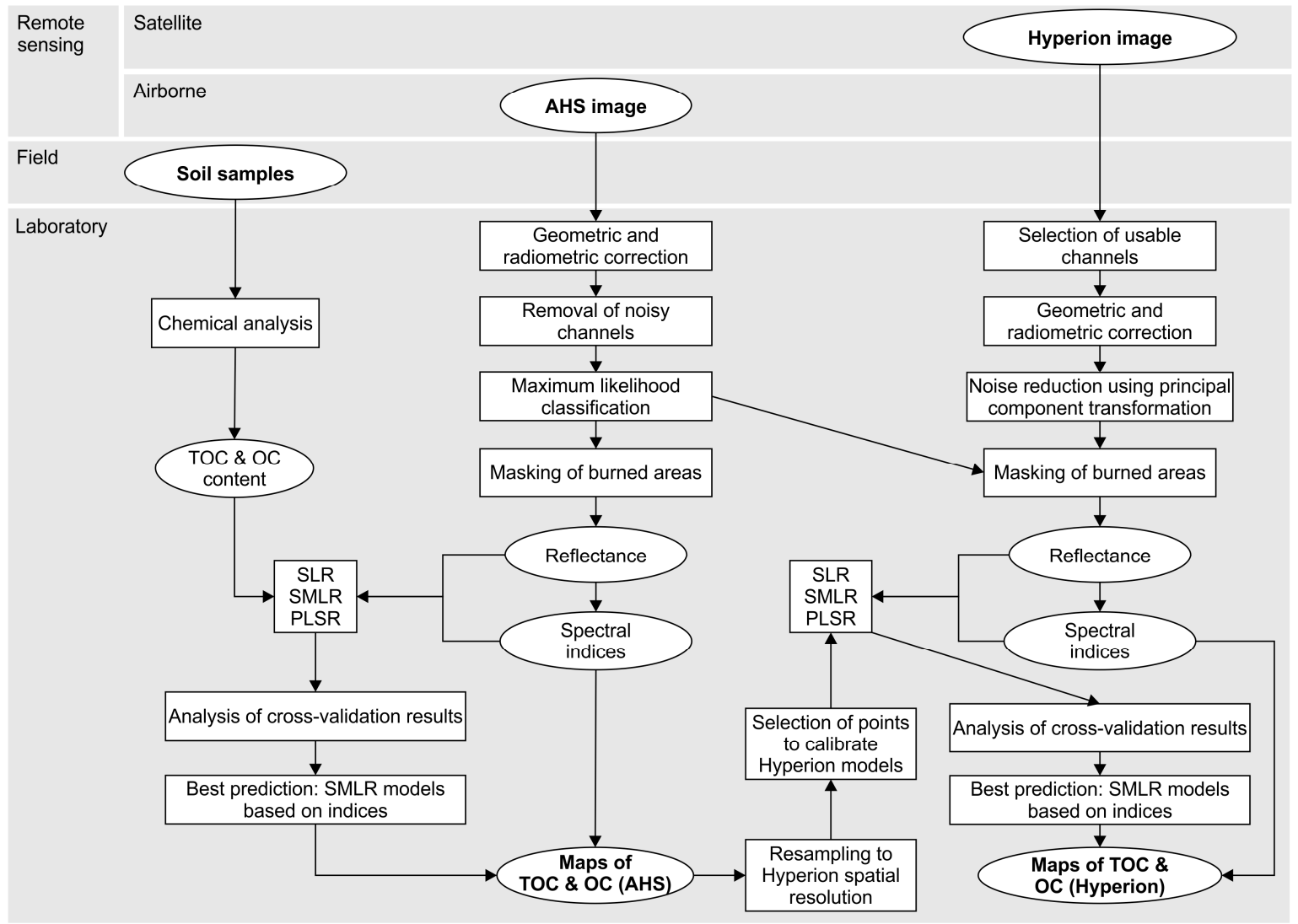

Figure 2. Flowchart of soil organic carbon (SOC) estimations (TOC and OC) using AHS and Hyperion hyperspectral data. $\mathrm{TOC}=$ total organic carbon; $\mathrm{OC}=$ oxidizable organic carbon; $\mathrm{SLR}=$ simple linear regression; SMLR = stepwise multiple linear regression; PLSR = partial least squares regression.

TOC and OC predictions were also performed using stepwise multiple linear regression (SMLR). The optimum set of variables of each model was determined automatically using a combined forward 
and backward selection method [67]. Only variables that remained significant at p-values lower than 0.05 were retained in the models. Two types of SMLR models were performed, using the reflectance of each AHS channel and spectral indices. As the number of variables (38 AHS channels and 1406 spectral indices) was similar to or greater than the number of observations (39 soil samples), only the most reliable channels and indices were selected for the SMLR analysis. The most reliable channels were those with the highest coefficients of determination $\left(\mathrm{R}^{2}\right)$ obtained in the SLR models. The identification of the most reliable indices was performed in two steps to avoid duplicate AHS channels in the list of indices selected for SMLR. First, the reference wavelength $\left(\lambda_{2}\right)$ of the index with the highest $R^{2}$ in the SLR was identified. Then, only the indices based on this reference wavelength were selected, and those with the highest $\mathrm{R}^{2}$ were included in the SMLR analysis.

In addition, the PLSR method [68,69] was used to establish relationships between the AHS reflectance values and both soil properties, TOC and OC. AHS reflectance spectra were mean centered before the PLSR modeling, as this preprocessing technique improved the correlation with the soil properties. The optimum number of PLSR factors or latent variables was determined by leave-one-out cross-validation and defined by the Akaike Information Criterion (AIC), which is based on a compromise between model accuracy and complexity [70,71]. The PLSR coefficients (b) [69] and the variable importance for projection (VIP) [68] were used to identify the most important wavelengths in the PLSR models. Wavelengths with higher $b$ and VIP are considered more relevant [68]. The thresholds for $b$ were based on their standard deviations [72], and the thresholds for VIP were set to 1 , following the recommendations by Chong and Jun [73].

The performance of the SLR, SMLR, and PLSR models was assessed using three metrics obtained in the leave-one-out cross-validation: the coefficient of determination $\left(\mathrm{R}^{2} \mathrm{cv}\right)$, the root mean square error $\left(\mathrm{RMSE}_{\mathrm{CV}}\right)$, and the ratio of performance to deviation (RPD), which is the ratio between the standard deviation of the calibration set against the RMSE $\mathrm{CV}_{\mathrm{C}}$. The model having the highest RPD is considered the best model. The prediction ability of the models was classified by Chang and Laird [74] in three classes: category A (RPD > 2), B $(2>$ RPD > 1.4), and C (RPD < 1.4), which correspond to models with good, intermediate, and low prediction abilities, respectively.

TOC and OC SMLR models with the highest RPD were applied pixel by pixel to the AHS image, in order to generate 5-m resolution maps of the burned regions located in the study area.

\subsection{SOC Modelling Using Satellite Hyperspectral Data}

The same process used to estimate TOC and OC with AHS data was followed for the estimation with Hyperion data, but using a different calibration dataset. As only six out of the 39 soil samples were available for the Hyperion image, the reference TOC and OC values that were required to calibrate the models were obtained from the maps based on AHS data. The 5-m resolution maps of TOC and OC obtained using the best SMLR models for AHS, which were those based on spectral indices, were resampled to the $30-\mathrm{m}$ resolution of the Hyperion image. Data of 36 pixels $(6 \times 6$ pixels $)$ with a spatial resolution of $5 \mathrm{~m}$ were aggregated and averaged to generate data with a spatial resolution of $30 \mathrm{~m}$. Two hundred points were selected in both TOC and OC maps, in burned areas delimited by the classification of the AHS image. TOC and OC values were extracted for the location of these points and related to the reflectances and spectral indices obtained from the Hyperion image. Then, SLR, SMLR, and PLSR models were calibrated following the process described in Section 2.6. The performance of the models was also assessed using the $\mathrm{R}^{2}{ }_{\mathrm{cv}}, \mathrm{RMSE}_{\mathrm{cV}}$, and RPD values. In addition, a stochastic simulation using the Monte Carlo method [75,76] was performed to analyze the error propagation in the best TOC and OC models for Hyperion. In the simulation, normal distribution of the errors was assumed using the Shapiro-Wilk test [77], and the number of iterations was set to 10,000 to obtain reliable results. The TOC and OC SMLR models with the highest RPD values were applied to the Hyperion image to generate 30-m resolution maps of the burned regions located in the study area. 


\section{Results}

\subsection{Descriptive Statistics of SOC}

Summary statistics of SOC are shown in Table 1. The results of the chemical analysis of the 39 soil samples showed that the study area was heterogeneous, with large variations in both TOC and OC, which is in good agreement with the results obtained in previous studies in this region [54,78]. TOC and OC maximum values were relatively high (greater than 35\%) and related to the high amount of organic matter accumulated in the existing paleo surfaces. The minimum values of TOC (4.3\%) and OC $(2.7 \%)$ occurred in soils located in burned slopes, which are characterized by very thin organic horizons as a result of the frequent fires [79]. Higher TOC and OC values were obtained in the north and center of the study area, and lower values were obtained in the south. A high positive correlation was found between TOC and OC $(\mathrm{R}=0.97)$. The distribution of TOC and OC values in the dataset used for Hyperion was similar to the distribution observed in the ground observation dataset.

Table 1. Descriptive statistics of soil organic carbon (SOC).

\begin{tabular}{ccccc}
\hline & \multicolumn{2}{c}{$\begin{array}{c}\text { Ground Observation Dataset } \\
\text { Used for AHS }(\boldsymbol{n}=\mathbf{3 9 )}\end{array}$} & \multicolumn{2}{c}{$\begin{array}{c}\text { Dataset Predicted by AHS } \\
\text { Used for Hyperion }(\boldsymbol{n}=\mathbf{2 0 0})\end{array}$} \\
\cline { 2 - 5 } & TOC $(\mathbf{\%})$ & OC $\mathbf{( \% )}$ & TOC $\mathbf{( \% )}$ & OC $\mathbf{( \% )}$ \\
\hline Minimum & 4.3 & 2.7 & 5.3 & 5.6 \\
Maximum & 51.7 & 37.9 & 51.6 & 37.4 \\
Mean & 33.3 & 22.5 & 34.4 & 22.9 \\
Standard deviation & 14.6 & 10.3 & 10.6 & 5.9 \\
\hline
\end{tabular}

AHS = Airborne Hyperspectral Scanner; $n=$ number of samples; TOC = total organic carbon; OC = oxidizable organic carbon.

\subsection{Correlation between SOC and Reflectances/Spectral Indices}

The correlation coefficient $\mathrm{R}$ was calculated at each wavelength between soil properties, TOC and OC, and reflectances from the AHS and Hyperion images (Figure 3). A relatively high negative correlation was observed in several wavelengths of the spectrum, with $\mathrm{R}$ between -0.5 and -0.65 , approximately. Darker soils, with lower reflectance, usually have higher organic matter content $[80,81]$, which explains the negative correlation observed in Figure 3.

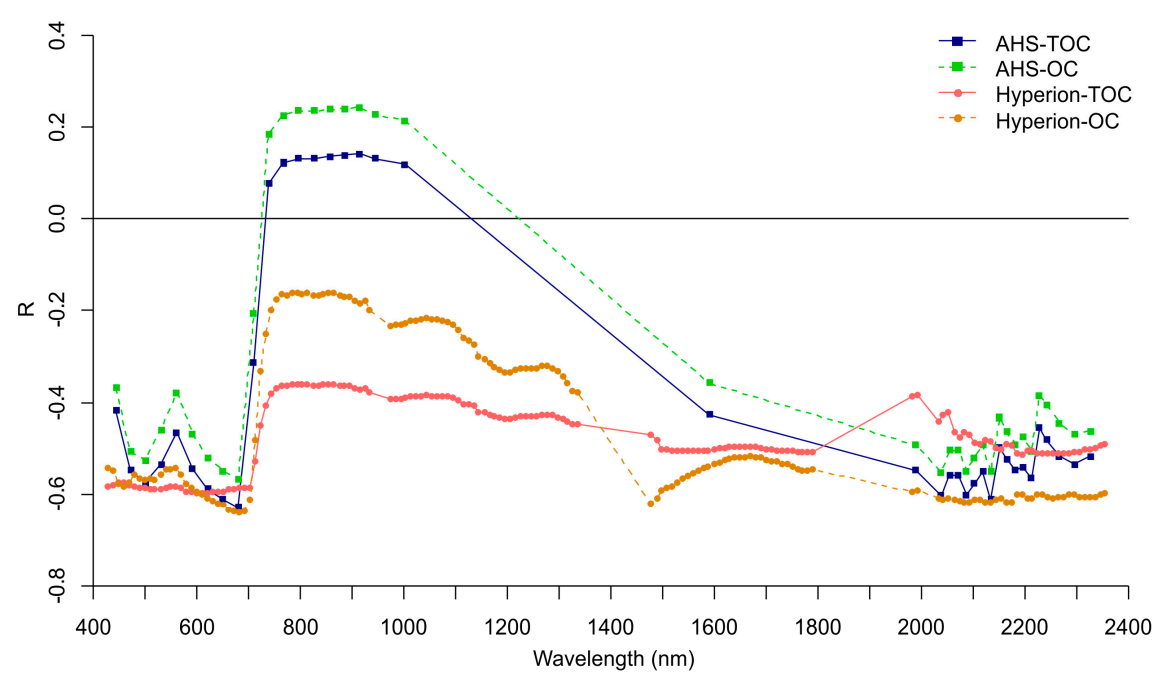

Figure 3. Pearson correlation coefficient between the TOC and OC content and the reflectance values from the AHS and Hyperion images. 
In general, the spectral regions with high correlation in Figure 3 were quite similar. The highest correlations for both soil properties and both sensors were found in the red region of the spectrum, with the maximum absolute correlation at the wavelengths at 610 and $679-681 \mathrm{~nm}$. These results are consistent with those of Stevens et al. [8], who also used AHS data to estimate SOC and found an absorption feature around 600-750 nm possibly related to SOC. Bartholomeus et al. [51] estimated SOC using laboratory reflectance spectra in the VIS-NIR-SWIR, and also found the red region to be important for SOC prediction, with the highest correlation observed at $\sim 600 \mathrm{~nm}$ using reflectance values, and between 640-690 $\mathrm{nm}$ using the inverse of the reflectance values. Vinogradov [82] also found the highest correlation between SOC and radiance in the red region of the spectrum $(600-700 \mathrm{~nm})$.

TOC and OC also showed high correlation in the SWIR region. Several wavelengths between 2100-2500 nm are known to be sensitive to soil organic matter content [83,84], which can explain the relatively high correlations found in this region. The high correlation in the SWIR region is in accordance with the results obtained in a previous study in the same area by Fernández et al. [38] using laboratory reflectance spectra. They found the SWIR, mainly between $2100-2350 \mathrm{~nm}$, to be the most significant region for SOC prediction, with the most important wavelength at $2212 \mathrm{~nm}$. The correlation between SOC and AHS reflectances showed chaotic features in the 2038-2326 nm region (Figure 3). These features were attributed to noise, considering that the AHS channels located in this region are characterized by a low SNR (mean SNR =18). A similar pattern was observed at these wavelengths in previous studies based on AHS data [8]. In contrast, the correlation for the Hyperion sensor was smoother at these wavelengths, despite the low SNR of Hyperion in the SWIR (SNR $=40$ at $2125 \mathrm{~nm}$ ). The smoothed correlograms obtained for the Hyperion image could be related to the noise reduction method based on principal components that was applied to the Hyperion image, which was more effective than the method used in the AHS image, based on the elimination of the channels with lower SNR.

In order to identify the most important wavelengths to estimate SOC using spectral indices $\mathrm{SI}_{\lambda 2-\lambda 1}$, all possible pair combinations of AHS/Hyperion channels in the VIS-NIR-SWIR region were evaluated. Spectral indices derived from the AHS and Hyperion images were correlated to SOC values using SLR. The coefficient of determination $\mathrm{R}^{2}$ between TOC/OC and spectral indices is shown in Figure 4. The results for the spectral indices based on AHS channels were very similar for TOC and OC. A significant region with $\mathrm{R}^{2} \gtrsim 0.5$ was found with combinations of AHS channels in the range $\lambda_{1}=591-679 \mathrm{~nm}$ and $\lambda_{2}=709-1001 \mathrm{~nm}$. It is noteworthy that $\lambda_{1}$ and $\lambda_{2}$ can be used interchangeably, as the $\mathrm{R}^{2}$ values in each graph of Figure 4 are symmetric with respect to the 1:1 line. A maximum $\mathrm{R}^{2}$ of 0.56 was obtained for both TOC and OC, with the AHS spectral index $\mathrm{SI}_{1001-679 \mathrm{~nm}}$, which is based on the effective band $\lambda_{1}=679 \mathrm{~nm}$ (red) related to chlorophyll absorption [85], and the reference band $\lambda_{2}=1001 \mathrm{~nm}$ (NIR) that can be associated with organic C [48]. This spectral index corresponds to the NDVI, which is based on the reflectance at a red and a NIR wavelength.

The analysis of the coefficient of determination $\mathrm{R}^{2}$ between TOC/OC and spectral indices from Hyperion showed lower or slightly lower $\mathrm{R}^{2}$ values than those obtained for AHS (Figure 4). The lower

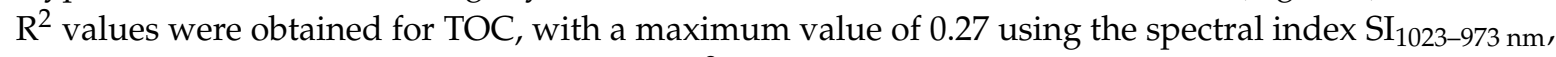
which is based on two NIR channels. Higher $\mathrm{R}^{2}$ values were found for OC. Relatively important regions for OC were $\lambda_{1}=539-610 \mathrm{~nm}$ and $\lambda_{2}=620-671 \mathrm{~nm}\left(\mathrm{R}^{2} \gtrsim 0.40\right), \lambda_{1}=630-712 \mathrm{~nm}$ and $\lambda_{2}=732-1336 \mathrm{~nm}$ $\left(\mathrm{R}^{2} \gtrsim 0.35\right), \lambda_{1}=732-1336 \mathrm{~nm}$ and $\lambda_{2}=1477-2355 \mathrm{~nm}\left(\mathrm{R}^{2} \gtrsim 0.30\right)$, and $\lambda_{1}=1508-1790 \mathrm{~nm}$ and $\lambda_{2}=2032-2254 \mathrm{~nm}\left(\mathrm{R}^{2} \gtrsim 0.30\right)$. A maximum $\mathrm{R}^{2}$ of 0.45 was obtained for the spectral index $\mathrm{SI}_{1033-973 \mathrm{~nm}}$. The Hyperion spectral indices with the highest correlation were consistent for TOC and OC, with $\lambda_{1}=973 \mathrm{~nm}$ and $\lambda_{2}=1023-1033 \mathrm{~nm}$ as the best band combinations. Wavelengths at $\sim 960 \mathrm{~nm}$ could be related to organic pigments, and those at $\sim 1020-1030 \mathrm{~nm}$ could be related to organic $C$ [48]. These wavelengths, which were found to be relevant for SOC estimations using Hyperion indices $\mathrm{SI}_{\lambda 2}-\lambda 1$, are not covered by the AHS sensor. 

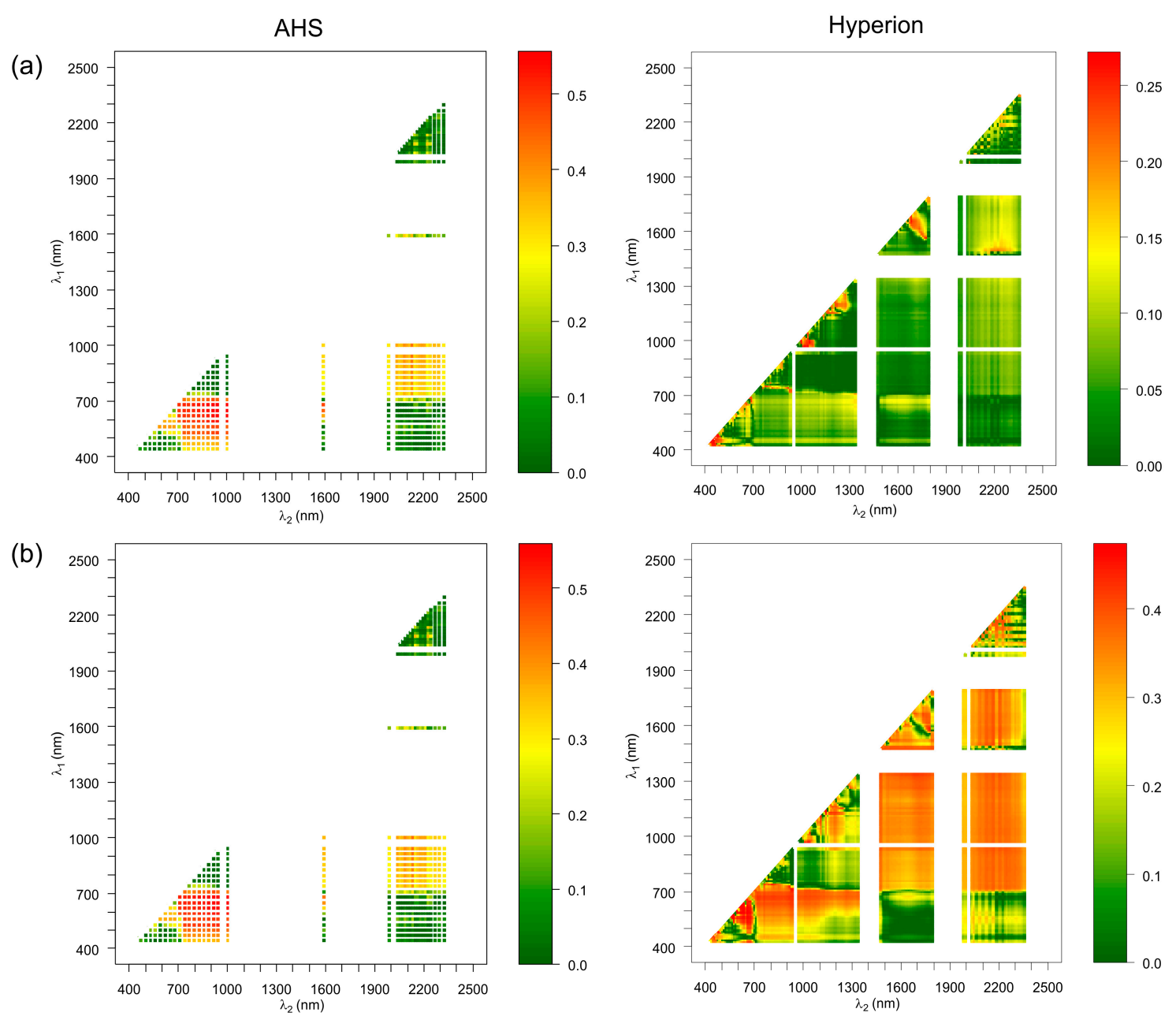

Figure 4. Coefficient of determination $\mathrm{R}^{2}$ between the TOC (a)/OC content (b) and the spectral indices $\mathrm{SI}_{\lambda 2-\lambda 1}=\left(\varrho_{\lambda 2}-\varrho_{\lambda 1}\right) /\left(\varrho_{\lambda 2}+\varrho_{\lambda 1}\right)$, based on AHS (left) and Hyperion (right) reflectance values. $R^{2}$ values in the graphs are symmetric with respect to the $1: 1$ line, and therefore $\lambda_{1}$ and $\lambda_{2}$ can be used interchangeably.

\subsection{SOC Predictive Models}

Several regression techniques (SLR, SMLR, and PLSR) were used to calibrate models for the estimation of TOC and OC via AHS/Hyperion reflectances and spectral indices $\mathrm{SI}_{\lambda 2-\lambda 1}$. Summary statistics of the leave-one-out cross-validation of the models for all soil properties, sensors, and regression techniques are gathered in Table 2. The best AHS/Hyperion channels and spectral indices for the estimation of both soil properties were identified and used to calibrate SLR models. The prediction equations of these models are listed in Table 2. In general, better SLR models were obtained for: the AHS sensor (mean RPD = 1.34) than for the Hyperion sensor (mean RPD = 1.25), OC (mean RPD = 1.31) than for TOC (mean RPD = 1.27), and spectral indices (mean RPD = 1.35) than for individual channels (mean RPD =1.24). According to the model classification by Chang and Laird [74] based on RPD values, the SLR models had low prediction ability, except for the SLR models for TOC/OC estimation using the AHS spectral index $\mathrm{SI}_{1001-679 \mathrm{~nm}}$, which showed an intermediate prediction ability $\left(\mathrm{R}_{\mathrm{cv}}^{2}=0.52\right.$ and $\mathrm{RPD}=1.46)$. 
Table 2. Leave-one-out cross-validation statistics of the regression models for soil organic $\mathrm{C}$ prediction using AHS and Hyperion data.

\begin{tabular}{|c|c|c|c|c|c|c|c|}
\hline Sensor & Soil Property & $\begin{array}{l}\text { Regression } \\
\text { Technique }\end{array}$ & Prediction Equation & $n$ & $\mathbf{R}^{2}{ }_{\mathrm{cv}}$ & $\mathrm{RMSE}_{\mathrm{cv}}(\%)$ & RPD \\
\hline \multirow[t]{10}{*}{ AHS } & \multirow[t]{5}{*}{ TOC (\%) } & SLR-1 channel & \multirow{3}{*}{$\begin{array}{c}\text { TOC }=66-1008 \times \varrho_{679} \mathrm{~nm} \\
\text { TOC }=-101+186 \times \mathrm{SI}_{1001-679 \mathrm{~nm}}\end{array}$} & 39 & 0.35 & 11.69 & 1.25 \\
\hline & & SLR-1 index & & 39 & 0.52 & 10.02 & 1.46 \\
\hline & & SMLR-3 channels & & 39 & 0.51 & 10.13 & 1.44 \\
\hline & & SMLR-8 indices & \multirow[t]{2}{*}{ See Table 3} & 39 & 0.62 & 9.05 & 1.62 \\
\hline & & PLSR-3 factors & & 39 & 0.49 & 10.39 & 1.41 \\
\hline & \multirow[t]{5}{*}{ OC $(\%)$} & SLR-1 channel & \multirow{3}{*}{$\begin{array}{c}\mathrm{OC}=43-640 \times \varrho_{679 \mathrm{~nm}} \\
\mathrm{OC}=-72+131 \times \mathrm{SI}_{1001-679 \mathrm{~nm}}\end{array}$} & 39 & 0.27 & 8.70 & 1.18 \\
\hline & & SLR-1 index & & 39 & 0.52 & 7.02 & 1.46 \\
\hline & & SMLR-3 channels & & 39 & 0.52 & 7.06 & 1.46 \\
\hline & & SMLR-2 indices & \multirow[t]{2}{*}{ See Table 3} & 39 & 0.60 & 6.44 & 1.60 \\
\hline & & PLSR-3 factors & & 39 & 0.48 & 7.34 & 1.40 \\
\hline \multirow[t]{10}{*}{ Hyperion } & \multirow[t]{5}{*}{ TOC (\%) } & SLR-1 channel & \multirow{3}{*}{$\begin{array}{c}\text { TOC }=58-356 \times \varrho_{610} \mathrm{~nm} \\
\text { TOC }=-46+2276 \times \mathrm{SI}_{1023-973 \mathrm{~nm}}\end{array}$} & 200 & 0.34 & 8.55 & 1.24 \\
\hline & & SLR-1 index & & 200 & 0.23 & 9.26 & 1.14 \\
\hline & & SMLR-15 channels & & 200 & 0.44 & 7.91 & 1.33 \\
\hline & & SMLR-18 indices & \multirow[t]{2}{*}{ See Table 3} & 200 & 0.49 & 7.58 & 1.39 \\
\hline & & PLSR-4 factors & & 200 & 0.32 & 8.68 & 1.22 \\
\hline & \multirow[t]{5}{*}{ OC (\%) } & SLR-1 channel & \multirow{3}{*}{$\begin{array}{c}\mathrm{OC}=33-177 \times \varrho_{681 \mathrm{~nm}} \\
\mathrm{OC}=-20+1218 \times \mathrm{SI}_{1033-973 \mathrm{~nm}}\end{array}$} & 200 & 0.40 & 4.59 & 1.29 \\
\hline & & SLR-1 index & & 200 & 0.43 & 4.48 & 1.32 \\
\hline & & SMLR-10 channels & & 200 & 0.54 & 4.02 & 1.48 \\
\hline & & SMLR-20 indices & \multirow[t]{2}{*}{ See Table 3} & 200 & 0.61 & 3.74 & 1.58 \\
\hline & & PLSR-4 factors & & 200 & 0.44 & 4.45 & 1.33 \\
\hline
\end{tabular}

$\mathrm{RMSE}_{\mathrm{CV}}=$ root mean square error of cross-validation; RPD = ratio of performance to deviation; SLR = simple linear regression; SMLR = stepwise multiple linear regression; PLSR = partial least squares regression; $\mathrm{SI}=\mathrm{spectral}$ index.

SMLR models were calibrated in order to improve the estimation of TOC and OC based on SLR. Two types of SMLR models were performed using reflectances of the AHS/Hyperion channels and spectral indices. The cross-validation statistics of the SMLR models are shown in Table 2. Models based on SMLR performed better that those based on SLR, for both soil properties and for both sensors. In all cases, the SMLR models based on spectral indices showed better results than the models based on reflectances. The most reliable SMLR models were obtained for AHS with spectral indices based on the reference channel at $1001 \mathrm{~nm}$, using eight indices for TOC $\left(\mathrm{R}_{\mathrm{cv}}^{2}=0.62\right.$ and $\left.\mathrm{RMSE}_{\mathrm{cv}}=9.05 \%\right)$, and two indices for $\mathrm{OC}\left(\mathrm{R}_{\mathrm{cv}}^{2}=0.60\right.$ and $\left.\mathrm{RMSE}_{\mathrm{cv}}=6.44 \%\right)$. Both models showed a relatively good performance, with the RPD $\geq 1.60$, which corresponds to models with an intermediate prediction ability, according to Chang and Laird [74]. The performance of the SMLR models based on indices was slightly lower for Hyperion. The model for Hyperion to estimate TOC was based on indices with the reference channel at $1023 \mathrm{~nm}$, and showed $\mathrm{R}_{\mathrm{cv}}^{2}=0.49, \mathrm{RMSE}_{\mathrm{cv}}=7.58 \%$, and a low /intermediate prediction ability, with the RPD $=1.39$. A slightly lower RPD value was obtained in the Monte Carlo simulation performed to analyze the error propagation in this model (mean RPD $=1.23$ ). The SMLR model for OC, based on indices with the reference channel at $1033 \mathrm{~nm}$, was more reliable, showing an $\mathrm{R}^{2}{ }_{\mathrm{cv}}=0.61, \mathrm{RMSE}_{\mathrm{cv}}=3.74 \%$, and $\mathrm{RPD}=1.58$. A lower $\mathrm{RPD}$ value was also obtained in the Monte Carlo simulation performed for this model (mean RPD $=1.20$ ). The prediction equations of the SMLR models based on indices are shown in Table 3.

The estimation of TOC and OC was also performed with the PLSR method. AHS/Hyperion reflectance spectra were mean centered before the PLSR modeling, as this preprocessing technique improved the RPD. The optimum number of factors-three for AHS and four for Hyperion models-was determined by leave-one-out cross-validation, using the AIC. The cross-validation statistics and the number of factors of the PLSR models are shown in Table 2. The validation of the PLSR models for AHS showed the RPD $=1.40-1.41$, which fall within the intermediate class of RPD, and $R^{2}{ }_{c v}=0.48-0.49$. Slightly lower values were obtained for the PLSR models for Hyperion, with $\mathrm{R}^{2}{ }_{\mathrm{cv}}=0.32-0.44$ and $\mathrm{RPD}=1.22-1.33$.

The accuracy of the regression models was higher using SMLR than PLSR. The SMLR models based on spectral indices showed higher $R^{2}{ }_{\mathrm{cv}}$ and RPD values than PLSR, and also lower RMSE $\mathrm{cv}_{\mathrm{cv}}$. This result is unexpected, since it is supposed that PLSR performs better than SMLR, considering that hyperspectral reflectance spectra are usually affected by multicollinearity, and PLSR is able to handle 
it. The PLSR results might be improved to obtain similar values to SMLR by applying further spectra preprocessing techniques, which usually increase the RPD. However, the use of more sophisticated preprocessing techniques was discarded in this work, in which the PLSR models were only included as a reference. SMLR was also found to perform better than PLSR in previous studies that used hyperspectral data to estimate soil properties [22]. These authors pointed out that a large calibration dataset would be required for further research on this issue.

Table 3. Expressions of the best SMLR models for soil organic $C$ estimation using AHS and Hyperion data. The prediction equation of each model is $S=b_{0}+b_{1} \times S_{\lambda 2-\lambda 1,1}+b_{2} \times S_{\lambda 2-\lambda 1,2}+\ldots+b_{n} \times$ $\mathrm{SI}_{\lambda 2-\lambda 1, n}$, where $\mathrm{S}$ is the soil property, $\mathrm{b}_{0}$ is the intercept, $\mathrm{b}_{1}-\mathrm{b}_{n}$ are the regression coefficients, and $\mathrm{SI}_{\lambda 2-\lambda 1}$ are the spectral indices, with the structure $\mathrm{SI}_{\lambda 2-\lambda 1}=\left(\varrho_{\lambda 2}-\varrho_{\lambda 1}\right) /\left(\varrho_{\lambda 2}+\varrho_{\lambda 1}\right)$.

\begin{tabular}{|c|c|c|c|c|c|c|c|}
\hline \multicolumn{4}{|c|}{ AHS } & \multicolumn{4}{|c|}{ Hyperion } \\
\hline \multicolumn{2}{|c|}{ TOC (\%) } & \multicolumn{2}{|c|}{ OC (\%) } & \multicolumn{2}{|c|}{ TOC (\%) } & \multicolumn{2}{|l|}{ OC (\%) } \\
\hline $\mathbf{b}_{0-n}$ & $\mathrm{SI}_{\lambda 2-\lambda 1,1-n}$ & $\mathbf{b}_{0-n}$ & $\mathrm{SI}_{\lambda 2-\lambda 1,1-n}$ & $\mathbf{b}_{0-n}$ & $\mathrm{SI}_{\lambda 2-\lambda 1,1-n}$ & $\mathbf{b}_{0-n}$ & $\mathrm{SI}_{\lambda 2-\lambda 1,1-n}$ \\
\hline $\begin{array}{c}-192 \\
1679 \\
-3941 \\
3325 \\
-2432 \\
1991 \\
-494 \\
276 \\
-198\end{array}$ & $\begin{array}{l}\mathrm{SI}_{1001-471} \mathrm{~nm} \\
\mathrm{SI}_{1001-500 \mathrm{~nm}} \\
\mathrm{SI}_{1001-530 \mathrm{~nm}} \\
\mathrm{SI}_{1001-591 \mathrm{~nm}} \\
\mathrm{SI}_{1001-620 \mathrm{~nm}} \\
\mathrm{SI}_{1001-709 \mathrm{~nm}} \\
\mathrm{SI}_{1001-2102 \mathrm{~nm}} \\
\mathrm{SI}_{1001-2150 \mathrm{~nm}}\end{array}$ & $\begin{array}{c}-116 \\
249 \\
-82\end{array}$ & $\begin{array}{l}\mathrm{SI}_{1001-679 \mathrm{~nm}} \\
\mathrm{SI}_{1001-2150 \mathrm{~nm}}\end{array}$ & $\begin{array}{c}-29 \\
-1693 \\
-24,127 \\
19,806 \\
-24,888 \\
24,104 \\
-31,871 \\
26,902 \\
-10,102 \\
-12,028 \\
-14,115 \\
18,239 \\
13,523 \\
-9758 \\
7336 \\
8275 \\
9878 \\
-11,850 \\
-3555\end{array}$ & $\begin{array}{l}\mathrm{SI}_{1023-844} \mathrm{~nm} \\
\mathrm{SI}_{1023-1064 \mathrm{~nm}} \\
\mathrm{SI}_{1023-1094 \mathrm{~nm}} \\
\mathrm{SI}_{1023-1104 \mathrm{~nm}} \\
\mathrm{SI}_{1023-1114 \mathrm{~nm}} \\
\mathrm{SI}_{1023-1185 \mathrm{~nm}} \\
\mathrm{SI}_{1023-1245 \mathrm{~nm}} \\
\mathrm{SI}_{1023-1316 \mathrm{~nm}} \\
\mathrm{SI}_{1023-1498 \mathrm{~nm}} \\
\mathrm{SI}_{1023-1558 \mathrm{~nm}} \\
\mathrm{SI}_{1023-1588 \mathrm{~nm}} \\
\mathrm{SI}_{1023-1790 \mathrm{~nm}} \\
\mathrm{SI}_{1023-1982 \mathrm{~nm}} \\
\mathrm{SI}_{1023-1992 \mathrm{~nm}} \\
\mathrm{SI}_{1023-2052 \mathrm{~nm}} \\
\mathrm{SI}_{1023-2103 \mathrm{~nm}} \\
\mathrm{SI}_{1023-2163 \mathrm{~nm}} \\
\mathrm{SI}_{1023-2355 \mathrm{~nm}}\end{array}$ & $\begin{array}{c}-172 \\
-2128 \\
-4832 \\
5509 \\
6087 \\
-8698 \\
4859 \\
-1368 \\
-17,970 \\
12772 \\
14470 \\
8856 \\
-11,975 \\
-6386 \\
9555 \\
4928 \\
-4845 \\
-6318 \\
-5679 \\
4452 \\
5356\end{array}$ & $\begin{array}{l}\mathrm{SI}_{1033-427 \mathrm{~nm}} \\
\mathrm{SI}_{1033-457 \mathrm{~nm}} \\
\mathrm{SI}_{1033-468 \mathrm{~nm}} \\
\mathrm{SI}_{1033-539 \mathrm{~nm}} \\
\mathrm{SI}_{1033-569 \mathrm{~nm}} \\
\mathrm{SI}_{1033-590 \mathrm{~nm}} \\
\mathrm{SI}_{1033-925 \mathrm{~nm}} \\
\mathrm{SI}_{1033-983 \mathrm{~nm}} \\
\mathrm{SI}_{1033-993 \mathrm{~nm}} \\
\mathrm{SI}_{1033-1044} \mathrm{~nm} \\
\mathrm{SI}_{1033-1266} \mathrm{~nm} \\
\mathrm{SI}_{1033-1276} \mathrm{~nm} \\
\mathrm{SI}_{1033-1639} \mathrm{~nm} \\
\mathrm{SI}_{1033-1679} \mathrm{~nm} \\
\mathrm{SI}_{1033-2083 \mathrm{~nm}} \\
\mathrm{SI}_{1033-2153 \mathrm{~nm}} \\
\mathrm{SI}_{1033-2163 \mathrm{~nm}} \\
\mathrm{SI}_{1033-2194 \mathrm{~nm}} \\
\mathrm{SI}_{1033-2214 \mathrm{~nm}} \\
\mathrm{SI}_{1033-2244}\end{array}$ \\
\hline
\end{tabular}

\subsection{Relevant Wavelengths for SOC Prediction}

The most important wavelengths in the regression models for TOC/OC prediction using AHS and Hyperion data are shown in Figure 5, in which the AHS and Hyperion channels used in this work were also included. In the SLR and SMLR models based on indices $\mathrm{SI}_{\lambda 2-\lambda 1}$, both $\lambda_{1}$ and $\lambda_{2}$ wavelengths were represented in Figure 5. The most important wavelengths in the PLSR models were those with both PLSR coefficients (b) greater than their standard deviations, and VIP values greater than 1. 


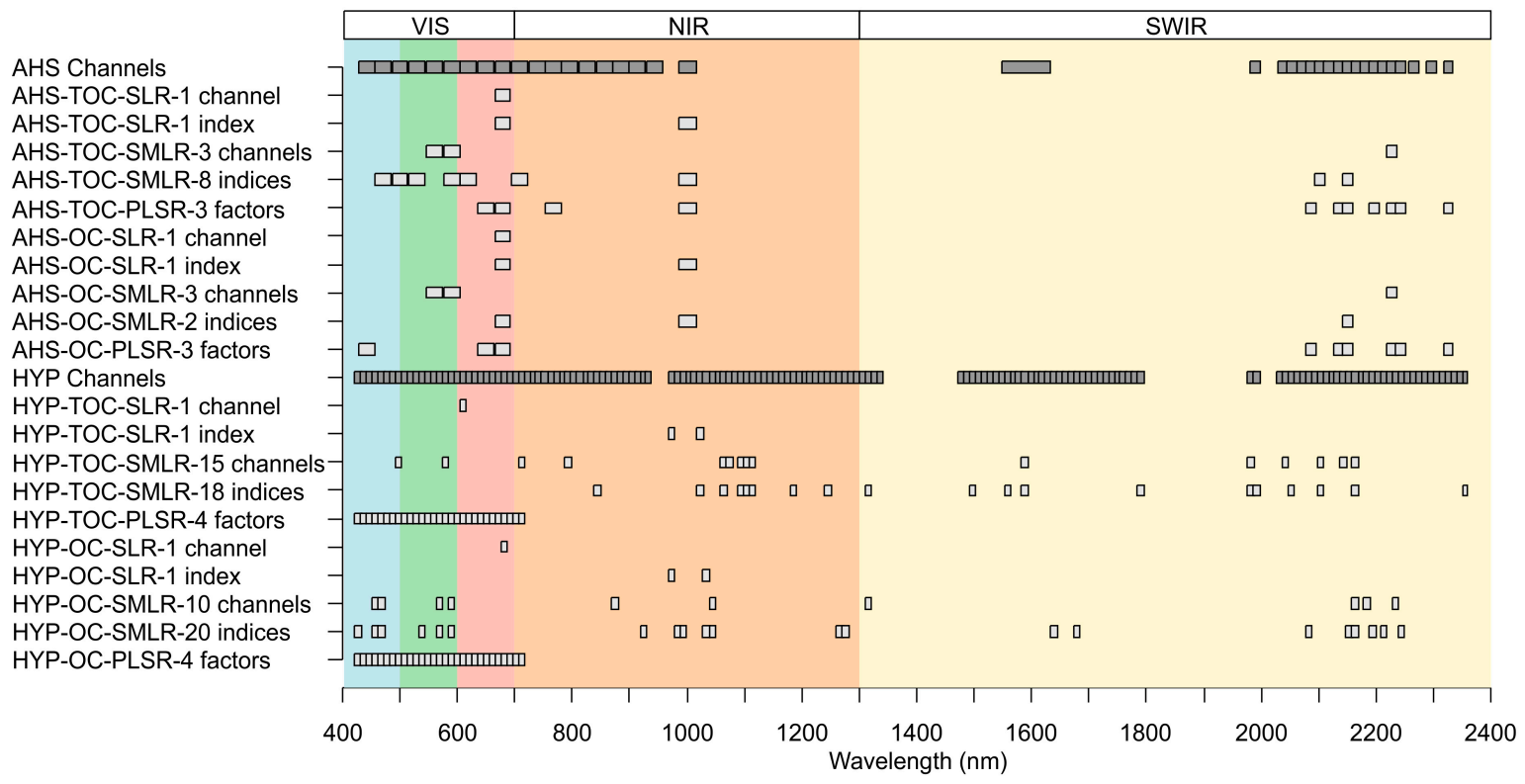

Figure 5. Important wavelengths in the regression models for TOC/OC estimation using AHS and Hyperion data. The width of each channel corresponds to the full width at half maximum (FWHM). AHS and Hyperion channels used in this study are represented in dark grey. HYP = Hyperion, VIS = visible; $\mathrm{NIR}=$ near infrared SWIR = short-wave infrared .

The AHS channel at $679 \mathrm{~nm}$ (red) and the AHS spectral index $\mathrm{SI}_{1001-679 \mathrm{~nm}}$ were relevant for TOC and OC prediction, according to the results shown in Section 3.2. The most accurate TOC/OC predictions for AHS were obtained using SMLR models based on indices with the reference wavelength at $1001 \mathrm{~nm}$, and effective wavelengths mainly in the red (620 and $679 \mathrm{~nm})$ and SWIR regions (2102 and $2150 \mathrm{~nm}$ ), although other wavelengths in the VIS region were also relevant for TOC. The red and SWIR regions were also important in the PLSR models for TOC/OC prediction. Several wavelengths between 2086-2326 nm were relevant in the PLSR models for AHS, but not in the SMLR models based on indices. However, the results obtained with both techniques were consistent, with the most important wavelengths in the red and SWIR regions. The red region of the spectrum was also relevant for the SOC and organic matter estimations in previous studies [8,51,82], and also the SWIR region, mainly between $2100-2500 \mathrm{~nm}[83,84]$. The AHS channel at $679 \mathrm{~nm}$ can be associated with chlorophyll absorption [85], and channels at 2102 and $2150 \mathrm{~nm}$ with lignin and recalcitrant $C[38,48,86]$.

Regarding the Hyperion sensor, channels in the red region of the spectrum $(610 \mathrm{~nm}$ and $681 \mathrm{~nm})$, and spectral indices based on channels in the NIR region $\left(\mathrm{SI}_{1023-973} \mathrm{~nm}\right.$ and $\left.\mathrm{SI}_{1033-973 \mathrm{~nm}}\right)$, were found to be relevant to estimate TOC and OC, as shown in Section 3.2. The most reliable models for Hyperion were the SMLR models based on indices, with the reference wavelength at 1023/1033 nm and effective wavelengths distributed across the VIS-NIR-SWIR region, especially from $983 \mathrm{~nm}$ onwards. Hyperion channels in the visible region between 427-712 nm were also important for TOC/OC prediction, according to the PLSR results. These channels correspond to the region with the best SNR of the Hyperion sensor [60]. In general, the most significant regions to estimate SOC using Hyperion are consistent with the results found in previous studies, in which the red $[8,51,82]$ and SWIR regions [83,84] were also important. Wavelengths at $\sim 960 \mathrm{~nm}, \sim 1020-1030 \mathrm{~nm}$, and $\sim 2000-2200 \mathrm{~nm}$ might be related to organic pigments, organic $C$, and carbon-hydrogen/nitrogen-hydrogen groups, respectively [48]. Other relevant wavelengths in the regression models could also be associated with organic compounds such as starch, lignin, and cellulose [64], but the attribution to a single component is difficult, as many compounds show overlapping bands in the region 700-2500 nm [87].

Although Hyperion has more channels, and narrower channels, than AHS, which are located in regions not covered by AHS that might be relevant for SOC estimation, the predictions were slightly 
worse for Hyperion than AHS. The larger number of indices involved in the SMLR models for Hyperion (18-20 indices) compared with AHS (2-8 indices) also reflects the relatively lower performance of the Hyperion models. These results were attributed to the lower SNR of the Hyperion sensor.

\subsection{SOC Mapping}

The best regression models for both sensors and both soil properties, which were based on SMLR and spectral indices (Table 3), were applied pixel by pixel to the geometrically and radiometrically corrected images. For illustration purposes, maps of TOC and OC content in the upper $5 \mathrm{~cm}$ of soils were obtained for the Combo site $\left(6^{\circ} 41^{\prime} 43.9^{\prime \prime} \mathrm{W}, 43^{\circ} 4^{\prime} 13.5^{\prime \prime} \mathrm{N}\right)$ (Figure 6). This site corresponds to a 20 ha burned slope located within the overlap region of the AHS and Hyperion images (see location in Figure 1). The altitude of Combo site varies along a NW-SE gradient, from $\sim 1230 \mathrm{~m}$ in the northwestern part of the slope to $\sim 900 \mathrm{~m}$ in the southeastern part. TOC and OC prediction at the Combo site was performed at two spatial resolutions, using the 5-m AHS image and the 30-m Hyperion image. Maps derived from the AHS image were smoothed by applying a mean filter with a window size of $3 \times 3$ pixels, to reduce residual noise and clearly show the spatial distribution of both TOC and OC.

(a)
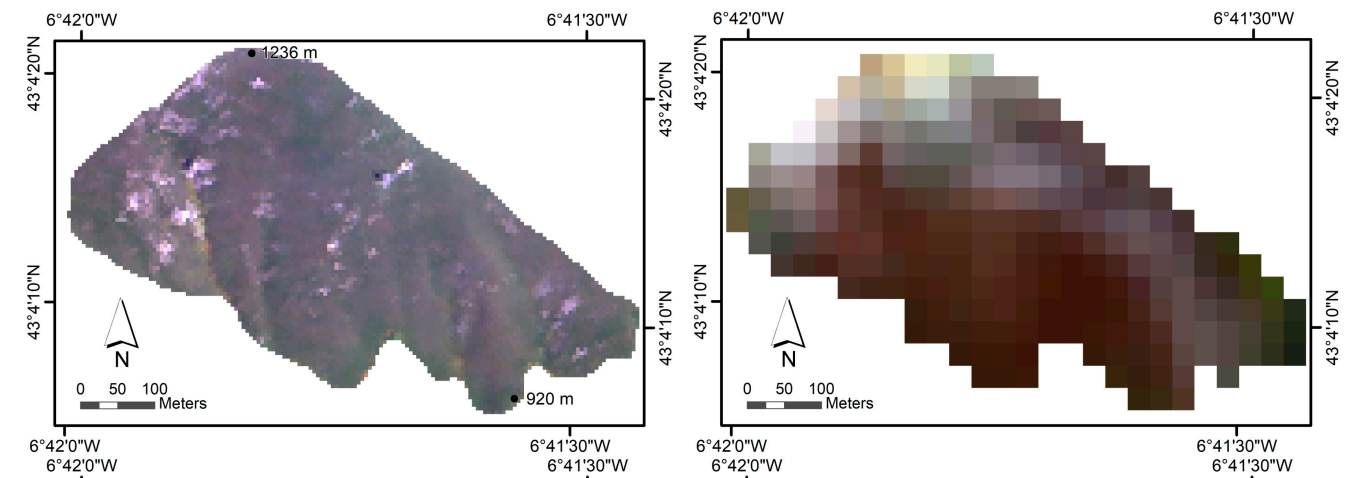

(b)
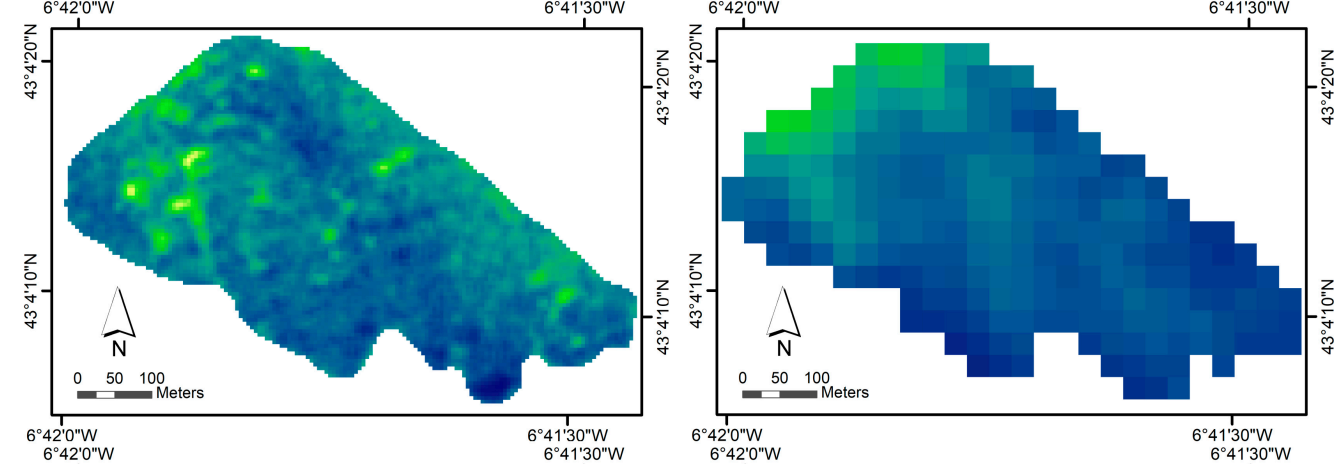

(c)
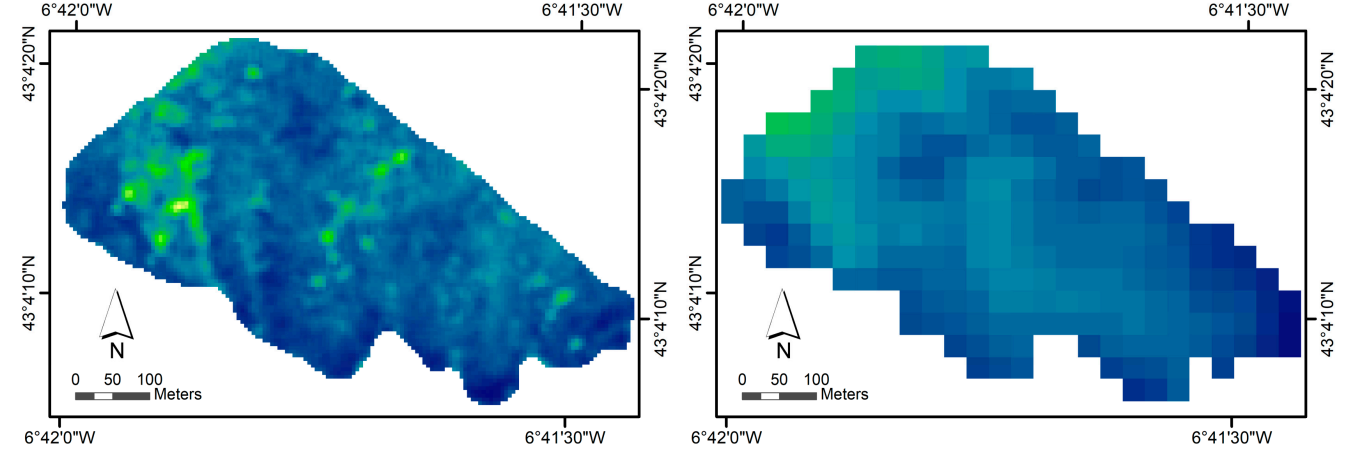

Figure 6. True-color composite (a) and maps of topsoil TOC (b) and OC content (c) predicted using the SMLR models based on spectral indices at the Combo site. Left: AHS image (airborne, spatial resolution of $5 \mathrm{~m}$ ). Right: Hyperion image (satellite, spatial resolution of $30 \mathrm{~m}$ ). The location of the Combo site is shown in Figure 1. 
The descriptive statistics of the maps in Figure 6 showed values in the same range as the calibration datasets, with mean TOC $=35.7-38.0 \%$ and mean OC $=21.2-22.4 \%$, for the maps based on the AHS and Hyperion images, respectively. In general, the prediction was consistent for the AHS and Hyperion images, despite the significant difference in their spatial resolution. The TOC content in the maps were higher than the OC content, as expected. TOC and OC content were also highly correlated in both the maps derived from AHS $(R=0.84)$ and Hyperion $(R=0.90)$. The spatial distribution of TOC and OC content within the slope seems to be linked to the altitude and topography, with lower contents in the upper areas, and higher contents in the lower and depressed areas. This distribution might be explained by local transfer processes such as the erosion, which led to the accumulation of SOC in the lower areas. The relief and topography were found to be related to SOC distribution in previous studies, which focused on agricultural fields $[8,21,23,88]$.

\section{Discussion}

The performance of the SMLR models based on spectral indices was compared with the results found in previous studies, in which SOC and organic matter were estimated using airborne and satellite hyperspectral data. The validation statistics of these studies are shown in Table 4, in which the results obtained in this study were also included for comparison purposes. The comparison was performed using the $\mathrm{R}^{2}$ and RPD values, and not the RMSE values, as they are not comparable among studies that estimate slightly different soil properties, which have different ranges of variation, and are expressed in different units.

SOC and organic matter were estimated in several studies using airborne hyperspectral imagery, with a number of channels between 20 and 282 in the VIS-NIR-SWIR region, and spatial resolutions ranging from $1 \mathrm{~m}$ to $8 \mathrm{~m}$. Most of these studies were aimed at estimating SOC over agricultural or bare soil areas. Only three out of 19 estimated SOC over areas partially covered by vegetation, all of them using PLSR [36-38]. The results obtained in this study using AHS data $\left(R^{2} \geq 0.60\right.$ and $\mathrm{RPD} \geq 1.60$ ) were in the range of those found in the literature. Bartholomeus et al. [37] used AHS data and the residual spectral unmixing technique to estimate SOC in fields partially covered by maize, and obtained slightly worse results in the validation $\left(R^{2}=0.56\right.$ and $\left.R P D=1.50\right)$. Fernández et al. [38] calibrated PLSR models using laboratory reflectance spectra that were subsequently applied to an AHS image to estimate SOC. They obtained slightly better results $\left(R^{2}=0.72-0.73\right.$ and $\left.R P D=1.89-1.92\right)$ than those obtained in this study. However, the application of the method proposed in Fernández et al. [38] is more complicated, as it requires the collection of laboratory reflectance spectra of the soil samples, as well as the determination of a correction factor to obtain soil maps from lab predictions. The model for organic matter prediction by Franceschini et al. [36] showed comparable results $\left(R^{2}=0.60\right.$ and $\mathrm{RPD}=1.60$ ) to those obtained here.

The validation results of previous studies that used airborne hyperspectral data to predict SOC/organic matter over agricultural or bare soil areas were heterogeneous, with $R^{2}$ between 0.02-0.96, and RPD values between 0.99 and 3.13. Denis et al. [29] obtained the best results $\left(R^{2}=0.96\right.$ and RPD $=3.13$ ) by correcting the soil shadow effect on the image reflectance through using a wavelength-dependent correction factor calculated from soil vertical photographs taken in the field. Stevens et al. [27] used a large dataset with 400 samples and obtained good results $\left(R^{2}=0.79\right.$ and $\mathrm{RPD}=2.33$ ) by performing local models for the different regions and soil textures found in the study area. The SOC prediction models by Hbirkou et al. [21] were calibrated using a relatively large dataset with 204 samples, and obtained good results in the validation $\left(R^{2}=0.83\right.$ and RPD $\left.=2.45\right)$. These authors also suggested the use of local calibrations for different surface conditions to improve the accuracy of the models. Most of the studies for SOC prediction over bare soil areas using airborne imagery were based on PLSR, and showed an intermediate prediction ability, with RPD values typically between 1.4 and 1.9, and $\mathrm{R}^{2}$ between $\sim 0.6-0.8$. 
Table 4. Validation statistics of previous studies for SOC/organic matter estimation using airborne and satellite hyperspectral data in the VIS-NIR-SWIR region.

\begin{tabular}{|c|c|c|c|c|c|c|c|c|c|}
\hline Sensor ${ }^{a}$ & $\begin{array}{l}\text { Spectral Range }(\mathrm{nm})^{\mathrm{b}} \text {, Number of } \\
\text { Bands, and Spatial Resolution }(\mathrm{m})\end{array}$ & Study Area (Country) ${ }^{\mathrm{c}}$ & Soil Property ${ }^{\mathrm{d}}$ & $\begin{array}{c}\text { Modeling } \\
\text { Technique }^{\mathrm{e}}\end{array}$ & $\mathrm{n}_{\text {cal }} \mid \mathrm{n}_{\mathrm{val}} \mathrm{f}$ & RMSE $\mathrm{g}$ & $\mathbf{R}^{2} \mathbf{g}$ & RPD $^{g}$ & Authors \\
\hline $\mathrm{AHS}^{*}$ & $400-1600$ (VNS), 21, 2.6 & Agric. fields (Belgium) & Corg. & PLSR (2) & 110 xval & $1.7 \mathrm{~g} / \mathrm{kg}$ & 0.54 & 1.47 & Stevens et al. [30] \\
\hline AHS * & $430-1600$ (VNS), 21, 2.6 & Agric. fields (Luxembourg) & Corg. & PLSR & $267 \mid 134$ & $4.3 \mathrm{~g} / \mathrm{kg}$ & 0.72 & 1.89 & Stevens et al. $[8]$ \\
\hline AHS * & 430-1600 (VNS), 21, 2.6 & Agric. fields (Luxembourg) & Corg. & PLSR & $400 \times \mathrm{xval}$ & $3.9 \mathrm{~g} / \mathrm{kg}$ & 0.79 & 2.33 & Stevens et al. [27] \\
\hline AHS * & $430-2540$ (VNS), 63, 2.6 & Agric. fields (Luxembourg) & Corg. & PLSR & $91 \mathrm{xval}$ & $3.7 \mathrm{~g} / \mathrm{kg}$ & 0.96 & 3.13 & Denis et al. [29] \\
\hline AHS * & $450-2120$ (VNS), 30, 2.6 & Partially vegetated agric. fields (Belgium) & Corg. & PLSR (8) & $52 \mid 16$ & $1.7 \mathrm{~g} / \mathrm{kg}$ & 0.56 & 1.50 & Bartholomeus et al. [37] \\
\hline AHS * & $442-1019(\mathrm{VN}), 20,2.6$ & Agric. fields (Luxembourg) & Corg. & PLSR & $46 \mid 31$ & $2.2 \mathrm{~g} / \mathrm{kg}$ & 0.74 & 1.9 & Steinberg et al. [28] \\
\hline AHS* & $430-2335$ (VNS), 38, 5 & Partially vegetated burned areas (Spain) & $\begin{array}{l}\text { C total } \\
\text { C oxid. }\end{array}$ & $\begin{array}{l}\text { PLSR (7) } \\
\text { PLSR (7) }\end{array}$ & $\begin{array}{l}89 \mid 10 \\
89 \mid 10\end{array}$ & $\begin{array}{l}7.8 \% \\
5.1 \%\end{array}$ & $\begin{array}{l}0.73 \\
0.72\end{array}$ & $\begin{array}{l}1.92 \\
1.89\end{array}$ & Fernández et al. [38] \\
\hline AHS* & $430-2335$ (VNS), 38, 5 & Partially vegetated burned areas (Spain) & $\begin{array}{l}\text { C total } \\
\text { C oxid. }\end{array}$ & $\begin{array}{l}\text { SMLR (8) } \\
\text { SMLR (2) }\end{array}$ & $\begin{array}{l}39 \text { xval } \\
39 \text { xval }\end{array}$ & $\begin{array}{l}9.1 \% \\
6.4 \%\end{array}$ & $\begin{array}{l}0.62 \\
0.60\end{array}$ & $\begin{array}{l}1.62 \\
1.60\end{array}$ & Peón et al. [this paper] \\
\hline HyMap * & 420-2480 (VNS), 127, 6 & Agric. fields (Germany) & $\begin{array}{l}\text { Corg. } \\
\text { C org. }\end{array}$ & $\begin{array}{l}\text { PLSR (7) } \\
\operatorname{MLR}(4)\end{array}$ & $\begin{array}{l}60 \mathrm{xval} \\
60 \mathrm{xval}\end{array}$ & $\begin{array}{l}0.29 \% \\
0.22 \%\end{array}$ & $\begin{array}{l}0.90 \\
0.86\end{array}$ & & Selige et al. [22] \\
\hline HyMap * & $450-2500$ (VNS), 128,4 & Agric. fields (Germany) & Corg. & PLSR & 9 xval & $1.6 \mathrm{~g} / \mathrm{kg}$ & 0.74 & & Patzold et al. [26] \\
\hline HyMap * & $420-2480$ (VNS), 110, 6 & Bare soils (Spain) & C total & PLSR & $61 \mid 61$ & $0.13 \%$ & 0.77 & 1.92 & Schwanghart and Jarmer [23] \\
\hline HyMap * & $450-2480$ (VNS), 128,4 & Agric. fields (Germany) & Corg. & PLSR (2) & 38129 & $2.1 \mathrm{~g} / \mathrm{kg}$ & 0.71 & 1.80 & Gerighausen et al. [24] \\
\hline HyMap * & $400-2500$ (VNS), 124,5 & Agric. fields (France) & Corg. & PLSR & $95 \mathrm{xval}$ & $2.6 \mathrm{~g} / \mathrm{kg}$ & 0.02 & 0.99 & Gomez et al. [25] \\
\hline HyMap * & 539-2477 (VNS), 126, 8 & Agric. fields (Germany) & Corg. & PLSR (7) & $204 \times \mathrm{xval}$ & $1.1 \mathrm{~g} / \mathrm{kg}$ & 0.83 & 2.45 & Hbirkou et al. [21] \\
\hline DAIS * & $400-2500$ (VNS), 69,8 & Agric. fields (Israel) & $\mathrm{OM}$ & MLR (4) & 6215 & & 0.83 & & Ben-Dor et al. [34] \\
\hline HSTIR * & $400-2450$ (VNS), 178, 2.5 & Agric. fields (USA) & C org. & PLSR (8) & $269 \mathrm{xval}$ & $0.18 \%$ & 0.64 & 1.39 & Hively et al. [35] \\
\hline P-AISA * & $400-2500$ (VNS), 282,1 & Weathered soils (Brazil) & $\mathrm{OM}$ & PLSR (8) & $60 \mathrm{xval}$ & $2.8 \mathrm{~g} / \mathrm{kg}$ & 0.60 & 1.60 & Franceschini et al. [36] \\
\hline AVNIR * & $429-1010(\mathrm{VN}), 60,1.2$ & Agric. fields (California) & $\begin{array}{l}\text { C total } \\
\mathrm{OM}\end{array}$ & $\begin{array}{l}\text { MLR (4) } \\
\text { MLR (4) }\end{array}$ & $\begin{array}{l}321 \mid- \\
321 \mid-\end{array}$ & $\begin{array}{l}0.08 \% \\
0.08 \%\end{array}$ & $\begin{array}{l}0.27 \\
0.49\end{array}$ & & DeTar et al. [33] \\
\hline CASI * & 409-947 (VN), 71, 2 & Agric. fields (Canada) & $\mathrm{OM}$ & PCA-SMLR & $47 \mathrm{xval}$ & $0.5 \%$ & 0.75 & 1.57 & Uno et al. [32] \\
\hline CASI * & $405-950$ (VN), 96, 6 & Agric. fields (Belgium) & Corg. & PLSR (2) & $170 \mid 57$ & $5.1 \mathrm{~g} / \mathrm{kg}$ & 0.85 & 1.86 & Stevens et al. [31] \\
\hline HYP ** & $427-2355$ (VNS), 152, 30 & Agric. fields and pastures (Australia) & Corg. & PLSR (3) & $72 \mathrm{xval}$ & $0.73 \%$ & 0.51 & 1.43 & Gomez et al. [39] \\
\hline HYP ** & 468-1770 (VNS), 98, 30 & Forests, pastures and agric. fields (USA) & Corg. & SMLR-ANN & 227176 & $11.3 \mathrm{t} / \mathrm{ha}$ & & 0.68 & Jaber et al. [43] \\
\hline HYP ** & 400-2500 (VNS), 158, 30 & Agric. fields (China) & Corg. & PLSR (3) & $47 \mathrm{xval}$ & $1.6 \mathrm{~g} / \mathrm{kg}$ & 0.63 & 1.65 & Lu et al. [40] \\
\hline HYP ** & 400-2500 (VNS), 150, 30 & Agric. fields (USA) & $\begin{array}{l}\text { C total } \\
\text { OM }\end{array}$ & $\begin{array}{l}\text { PLSR (3) } \\
\text { PLSR (4) }\end{array}$ & $\begin{array}{l}2018 \\
2018\end{array}$ & $\begin{array}{l}0.33 \% \\
0.66 \%\end{array}$ & $\begin{array}{l}0.48 \\
0.74\end{array}$ & $\begin{array}{l}1.48 \\
1.91\end{array}$ & Zhang et al. [41] \\
\hline HYP ** & $436-2345$ (VNS), 171,30 & Maize crops (Italy) & $\mathrm{OM}$ & OLS MNF & $72 \mathrm{xval}$ & $0.15 \%$ & & 2.93 & Castaldi et al. [42] \\
\hline HYP ** & $427-2335$ (VNS), 155,30 & Partially vegetated burned areas (Spain) & $\begin{array}{l}\text { C total } \\
\text { C oxid. }\end{array}$ & $\begin{array}{l}\text { SMLR (18) } \\
\text { SMLR (20) }\end{array}$ & $\begin{array}{l}200 \mathrm{xval} \\
200 \mathrm{xval}\end{array}$ & $\begin{array}{l}7.6 \% \\
3.7 \%\end{array}$ & $\begin{array}{l}0.49 \\
0.61\end{array}$ & $\begin{array}{l}1.39 \\
1.58\end{array}$ & Peón et al. [this paper] \\
\hline
\end{tabular}

a Asterisks indicate the sensor type: airborne $\left.{ }^{*}\right)$, satellite $\left.{ }^{(* *}\right)$. Sensor names: HSTIR = HyperSpecTIR, P-AISA = ProSpecTIR-AISA, HYP = Hyperion. ${ }^{\mathrm{b}}$ The spectral region is shown in brackets: visible $(\mathrm{V}, 400-700 \mathrm{~nm})$, near infrared $(\mathrm{N}, 700-1300 \mathrm{~nm})$, short-wave infrared $(\mathrm{S}, 1300-2500 \mathrm{~nm}) .{ }^{\mathrm{c}}$ Agric. fields $=$ agricultural fields. ${ }^{\mathrm{d}} \mathrm{C}$ org. $=\mathrm{C}$ organic, $\mathrm{C}$ oxid. $=\mathrm{C}$ oxidizable, $\mathrm{OM}=$ organic matter. ${ }^{\mathrm{e}} \mathrm{MLR}=$ multiple linear regression, $\mathrm{PCA}=$ principal component analysis, $\mathrm{ANN}=$ artificial neural network, OLS MNF $=$ ordinary least squares using the minimum noise fraction eigenvectors. The number of channels or PLSR factors used in the models is shown in brackets. ${ }^{f} n_{\text {cal }} \mid n_{\text {val }}$ indicate the number of samples used in the calibration and in the validation, respectively. " $x v a l$ " indicates that the validation was performed using the cross-validation technique. ${ }^{g}$ RMSE, $\mathrm{R}^{2}$, and RPD obtained in the validation. 
SOC has rarely been estimated using satellite hyperspectral data, and only the Hyperion sensor with a spatial resolution of $30 \mathrm{~m}$ was used (Table 4). The validation statistics obtained with Hyperion data in this study $\left(\mathrm{R}^{2}=0.49-0.61\right.$ and $\left.\mathrm{RPD}=1.39-1.58\right)$ were comparable to those found in bare soil or agricultural areas [39-41]. PLSR models obtained in these studies also provided an intermediate prediction ability, with $\mathrm{R}^{2}=0.48-0.74$, and $\mathrm{RPD}=1.43-1.91$. Regarding the studies in areas covered by vegetation, heterogeneous validation results were reported. The results obtained in this study were better than those reported by Jaber et al. [43], which used a large dataset with 227 samples to model SOC over forests, pastures, and agricultural fields, using SMLR and artificial neural networks. Their results using both SMLR and artificial neural networks were significantly better than those using only SMLR or PLSR, but their models showed a low prediction ability, with RPD $=0.68$. Castaldi et al. [42] used Hyperion data to estimate organic matter in maize crops and did not find significant differences between the validation results obtained under bare soil and vegetation cover conditions. They obtained PLSR models with low prediction ability (RPD $=1.02)$ under vegetation conditions, using a calibration dataset with organic matter in the range of 1.1-2.7\%. However, the performance of these models was improved significantly using the ordinary least squares technique and the minimum noise fraction $(\mathrm{MNF})$ eigenvectors instead of the reflectance spectra (RPD $=2.93$ ).

The results obtained in the Monte Carlo simulation that was performed to analyze the error propagation in the best models for the Hyperion sensor (mean RPD $=1.23$ for TOC and mean RPD $=1.20$ for OC) were slightly lower than those obtained in the cross-validation of the same models (Table 2), but still comparable to those found in previous studies in Table 4.

Based on the results obtained in previous studies for SOC estimation using either airborne or satellite hyperspectral data (Table 4), SOC prediction is expected to improve by using large datasets, which would allow the calibration of local models for the different regions and soil textures in the study area. The prediction could also be improved by applying methods to reduce the soil relative shadows, as well as using more sophisticated modeling techniques, such as multivariate adaptive regression splines (MARS) or artificial neural networks, which are currently used for SOC estimation with lab spectroscopy [11]. The use of the MNF transformation before modeling might effectively segregate the noise in the reflectance spectra and improve the estimation. The prediction of SOC over areas partially covered by vegetation might be improved with the application of spectral unmixing techniques.

However, the use of complex modeling techniques or methods that require extensive field data collection contrasts with the idea of operational soil mapping. Field campaigns for the collection of soil samples are expensive and time-consuming. The use of legacy data to calibrate models might be very profitable for operational soil mapping [89]. Efforts should also focus on the development of simple techniques to estimate SOC, such as the use of spectral indices in combination with SMLR. The identification of spectral regions that are important for SOC prediction could also help create new indices with high potential to be transferred to future hyperspectral sensors. Several next generation satellite VIS-NIR-SWIR hyperspectral sensors are planned to be launched, including: HISUI from Japan [90], PRISMA from Italy [91], and EnMAP from Germany in 2018 [92]; HYPXIM from France in 2020 [93]; SHALOM from Italy and Israel in 2021 [94]; and HyspIRI from USA in 2022 [95]. These hyperspectral sensors, which have spatial resolutions between $\sim 8-30 \mathrm{~m}$, are expected to provide higher SNRs than current sensors, especially in the SWIR region, and could allow for an operational quantitative SOC mapping at low cost with global coverage. SOC could be estimated using the forthcoming sensors PRISMA, EnMAP, and HyspIRI with an intermediate accuracy (RMSE about $0.2 \%$ and $\mathrm{R}^{2}$ between $~ 0.5-0.7$ ), according to the tests performed by Castaldi et al. [96] using simulated data.

\section{Conclusions}

Topsoil organic carbon was estimated using hyperspectral data acquired by an airborne sensor (AHS) and a satellite sensor (Hyperion), which are characterized by different spectral and spatial resolutions. The prediction was performed in burned mountain areas far from the bare soil ideal conditions, because they were slightly covered by heather. Despite the significant difference in the 
spectral and spatial resolution of the AHS and Hyperion images, SOC estimations were consistent using both sensors, and the validation results were comparable in terms of $\mathrm{R}^{2}$ and the RPD to those found in the literature, even to those reported in several studies that focused on agricultural fields or bare soil areas. Slightly worse results were obtained for the Hyperion sensor, and this was attributed to the lower SNR of this sensor.

SOC modeling using simple techniques such as SMLR based on spectral indices showed a performance comparable to the more complex PLSR method, but with several advantages, including the use of a lower number of channels (38/155 channels in PLSR and a maximum of 21 in SMLR) and easier application to the images. As the SOC prediction models were based on the simple SMLR technique and used a relatively low number of indices, they could be transferred easily to other hyperspectral sensors, such as the upcoming satellite hyperspectral sensors with improved SNR. These models might even be transferred to current or future multispectral sensors with bands at relevant wavelengths for SOC prediction. Important wavelengths to estimate SOC were the red region of the spectrum (600-700 nm), as well as the SWIR region between $\sim 2000-2250 \mathrm{~nm}$. The development of spectral indices based on these regions, in combination with the use of simple modeling techniques, might be very useful for increasing the applicability of these SOC mapping methods. Although the operational topsoil mapping using these methods still remains a challenge, the results showed the potential of hyperspectral sensors to estimate SOC.

Acknowledgments: This research was supported by the Government of Asturias through the project SV-PA-13-ECOEMP-40. J.P. acknowledges the following Ph.D. Grants: "FPU" from the Spanish Ministry of Education (FPU14/01350), "Severo Ochoa" from the Government of Asturias (BP14-104) and "Predoctoral Grant" from the University of Oviedo. INTA is gratefully acknowledged for the organization of the flight campaign and the geometric and radiometric correction of the AHS image. J.P. also acknowledges the help and technical assistance provided by the INTA team during his short stay for the radiometric correction of the Hyperion image. We thank Cristina Santín for comments about soil $\mathrm{C}$ analysis and Carlos Cabo for suggestions about error propagation.

Author Contributions: J.P., C.R., S.F. and J.F.C. contributed in the design of the study and performed the field sampling. J.P. designed and submitted the request for the acquisition of the Hyperion data, carried out the statistical analysis, the accuracy assessment and the interpretation of the results. He wrote and edited the paper. C.R. and S.F. supervised the study and assisted in the interpretation of the results. J.F.C. contributed to the critical analysis of the paper. E.D.M. and L.C. provided expertise in processing the imagery and performed the geometric and radiometric correction of the imagery in collaboration with J.P. and C.R. All authors contributed to proofreading and making comments on the manuscript.

Conflicts of Interest: The authors declare no conflict of interest.

\section{References}

1. Lal, R. Soil carbon sequestration impacts on global climate change and food security. Science 2004, 304, 1623-1627. [CrossRef] [PubMed]

2. Houghton, R.A. Balancing the global carbon budget. Annu. Rev. Earth Planet. Sci. 2007, 35, 313-347. [CrossRef]

3. Smith, P.; Gottschalk, P.; Smith, J. Climate change and soil carbon impacts. In Soil Carbon: Science, Management and Policy for Multiple Benefits; Banwart, S.A., Noellemeyer, E., Milne, E., Eds.; CABI: London, UK, 2014; pp. 235-242.

4. Lal, R. Challenges and opportunities in soil organic matter research. Eur. J. Soil Sci. 2009, 60, $158-169$. [CrossRef]

5. Sreenivas, K.; Dadhwal, V.K.; Kumar, S.; Harsha, G.S.; Mitran, T.; Sujatha, G.; Suresh, G.J.R.; Fyzee, M.A.; Ravisankar, T. Digital mapping of soil organic and inorganic carbon status in India. Geoderma 2016, 269, 160-173. [CrossRef]

6. Saiano, F.; Oddo, G.; Scalenghe, R.; La Mantia, T.; Ajmone-Marsan, F. DRIFTS sensor: Soil carbon validation at large scale (Pantelleria, Italy). Sensors 2013, 13, 5603-5613. [CrossRef] [PubMed]

7. Minasny, B.; McBratney, A.B.; Malone, B.P.; Wheeler, I. Digital mapping of soil carbon. In Advances in Agronomy; Sparks, D.L., Ed.; Elsevier Academic Press Inc.: San Diego, CA, USA, 2013; Volume 118, pp. 1-47. 
8. Stevens, A.; Udelhoven, T.; Denis, A.; Tychon, B.; Lioy, R.; Hoffmann, L.; van Wesemael, B. Measuring soil organic carbon in croplands at regional scale using airborne imaging spectroscopy. Geoderma 2010, 158, 32-45. [CrossRef]

9. Heiri, O.; Lotter, A.F.; Lemcke, G. Loss on ignition as a method for estimating organic and carbonate content in sediments: Reproducibility and comparability of results. J. Paleolimnol. 2001, 25, 101-110. [CrossRef]

10. Walkley, A.; Black, I.A. An examination of the Degtjareff method for determining soil organic matter, and a proposed modification of the chromic acid titration method. Soil Sci. 1934, 37, 29-38. [CrossRef]

11. Viscarra Rossel, R.A.; Walvoort, D.J.J.; McBratney, A.B.; Janik, L.J.; Skjemstad, J.O. Visible, near infrared, mid infrared or combined diffuse reflectance spectroscopy for simultaneous assessment of various soil properties. Geoderma 2006, 131, 59-75. [CrossRef]

12. Martin, P.D.; Malley, D.F.; Manning, G.; Fuller, L. Determination of soil organic carbon and nitrogen at the field level using near-infrared spectroscopy. Can. J. Soil Sci. 2002, 82, 413-422. [CrossRef]

13. Reeves, J.B.; McCarty, G.W. Quantitative analysis of agricultural soils using near infrared reflectance spectroscopy and a fibre-optic probe. J. Near Infrared Spectrosc. 2001, 9, 25-34. [CrossRef]

14. Mouazen, A.M.; Kuang, B.; De Baerdemaeker, J.; Ramon, H. Comparison among principal component, partial least squares and back propagation neural network analyses for accuracy of measurement of selected soil properties with visible and near infrared spectroscopy. Geoderma 2010, 158, 23-31. [CrossRef]

15. Nocita, M.; Kooistra, L.; Bachmann, M.; Mueller, A.; Powell, M.; Weel, S. Predictions of soil surface and topsoil organic carbon content through the use of laboratory and field spectroscopy in the Albany Thicket Biome of Eastern Cape Province of South Africa. Geoderma 2011, 167-168, 295-302. [CrossRef]

16. Reeves, J.B.; McCarty, G.W.; Meisinger, J.J. Near infrared reflectance spectroscopy for the analysis of agricultural soils. J. Near Infrared Spectrosc. 1999, 7, 179-193. [CrossRef]

17. Madari, B.E.; Reeves, J.B.; Machado, P.L.O.A.; Guimarães, C.M.; Torres, E.; McCarty, G.W. Mid- and near-infrared spectroscopic assessment of soil compositional parameters and structural indices in two Ferralsols. Geoderma 2006, 136, 245-259. [CrossRef]

18. Vohland, M.; Besold, J.; Hill, J.; Fründ, H.-C. Comparing different multivariate calibration methods for the determination of soil organic carbon pools with visible to near infrared spectroscopy. Geoderma 2011, 166, 198-205. [CrossRef]

19. Ben-Dor, E.; Chabrillat, S.; Dematte, J.A.M.; Taylor, G.R.; Hill, J.; Whiting, M.L.; Sommer, S. Using Imaging Spectroscopy to study soil properties. Remote Sens. Environ. 2009, 113, S38-S55. [CrossRef]

20. Croft, H.; Kuhn, N.J.; Anderson, K. On the use of remote sensing techniques for monitoring spatio-temporal soil organic carbon dynamics in agricultural systems. Catena 2012, 94, 64-74. [CrossRef]

21. Hbirkou, C.; Paetzold, S.; Mahlein, A.-K.; Welp, G. Airborne hyperspectral imaging of spatial soil organic carbon heterogeneity at the field-scale. Geoderma 2012, 175, 21-28. [CrossRef]

22. Selige, T.; Boehner, J.; Schmidhalter, U. High resolution topsoil mapping using hyperspectral image and field data in multivariate regression modeling procedures. Geoderma 2006, 136, 235-244. [CrossRef]

23. Schwanghart, W.; Jarmer, T. Linking spatial patterns of soil organic carbon to topography-A case study from south-eastern Spain. Geomorphology 2011, 126, 252-263. [CrossRef]

24. Gerighausen, H.; Menz, G.; Kaufmann, H. Spatially explicit estimation of clay and organic carbon content in agricultural soils using multi-annual imaging spectroscopy data. Appl. Environ. Soil Sci. 2012, 2012, 868090. [CrossRef]

25. Gomez, C.; Lagacherie, P.; Coulouma, G. Regional predictions of eight common soil properties and their spatial structures from hyperspectral Vis-NIR data. Geoderma 2012, 189, 176-185. [CrossRef]

26. Patzold, S.; Mertens, F.M.; Bornemann, L.; Koleczek, B.; Franke, J.; Feilhauer, H.; Welp, G. Soil heterogeneity at the field scale: A challenge for precision crop protection. Precis. Agric. 2008, 9, 367-390. [CrossRef]

27. Stevens, A.; Miralles, I.; van Wesemael, B. Soil organic carbon predictions by airborne imaging spectroscopy: Comparing cross-validation and validation. Soil Sci. Soc. Am. J. 2012, 76, 2174-2183. [CrossRef]

28. Steinberg, A.; Chabrillat, S.; Stevens, A.; Segl, K.; Foerster, S. Prediction of common surface soil properties based on Vis-NIR airborne and simulated EnMAP imaging spectroscopy data: Prediction accuracy and influence of spatial resolution. Remote Sens. 2016, 8, 613. [CrossRef]

29. Denis, A.; Stevens, A.; van Wesemael, B.; Udelhoven, T.; Tychon, B. Soil organic carbon assessment by field and airborne spectrometry in bare croplands: Accounting for soil surface roughness. Geoderma 2014, 226-227, 94-102. [CrossRef] 
30. Stevens, A.; van Wesemael, B.; Bartholomeus, H.; Rosillon, D.; Tychon, B.; Ben-Dor, E. Laboratory, field and airborne spectroscopy for monitoring organic carbon content in agricultural soils. Geoderma 2008, 144, 395-404. [CrossRef]

31. Stevens, A.; van Wesemael, B.; Vandenschrick, G.; Toure, S.; Tychon, B. Detection of carbon stock change in agricultural soils using spectroscopic techniques. Soil Sci. Soc. Am. J. 2006, 70, 844-850. [CrossRef]

32. Uno, Y.; Prasher, S.O.; Patel, R.M.; Strachan, I.B.; Pattey, E.; Karimi, Y. Development of field-scale soil organic matter content estimation models in Eastern Canada using airborne hyperspectral imagery. Can. Biosyst. Eng. 2005, 47, 9-14.

33. DeTar, W.R.; Chesson, J.H.; Penner, J.V.; Ojala, J.C. Detection of soil properties with airborne hyperspectral measurements of bare fields. Trans. ASABE 2008, 51, 463-470. [CrossRef]

34. Ben-Dor, E.; Patkin, K.; Banin, A.; Karnieli, A. Mapping of several soil properties using DAIS-7915 hyperspectral scanner data-A case study over clayey soils in Israel. Int. J. Remote Sens. 2002, 23, 1043-1062. [CrossRef]

35. Hively, W.D.; McCarty, G.W.; Reeves, J.B.; Lang, M.W.; Oesterling, R.A.; Delwiche, S.R. Use of airborne hyperspectral imagery to map soil properties in tilled agricultural fields. Appl. Environ. Soil Sci. 2011, 2011, 358193. [CrossRef]

36. Franceschini, M.H.D.; Demattê, J.A.M.; da Silva Terra, F.; Vicente, L.E.; Bartholomeus, H.; de Souza Filho, C.R. Prediction of soil properties using imaging spectroscopy: Considering fractional vegetation cover to improve accuracy. Int. J. Appl. Earth Obs. 2015, 38, 358-370. [CrossRef]

37. Bartholomeus, H.; Kooistra, L.; Stevens, A.; van Leeuwen, M.; van Wesemael, B.; Ben-Dor, E.; Tychon, B. Soil Organic Carbon mapping of partially vegetated agricultural fields with imaging spectroscopy. Int. J. Appl. Earth Obs. 2011, 13, 81-88. [CrossRef]

38. Fernández, S.; Peón, J.; Recondo, C.; Calleja, J.F.; Guerrero, C. Spatial modelling of organic carbon in burned mountain soils using hyperspectral images, field datasets, and NIR spectroscopy (Cantabrian Range; NW Spain). Land Degrad. Dev. 2016, 27, 1479-1488. [CrossRef]

39. Gomez, C.; Viscarra Rossel, R.A.; McBratney, A.B. Soil organic carbon prediction by hyperspectral remote sensing and field vis-NIR spectroscopy: An Australian case study. Geoderma 2008, 146, 403-411. [CrossRef]

40. Lu, P.; Wang, L.; Niu, Z.; Li, L.; Zhang, W. Prediction of soil properties using laboratory VIS-NIR spectroscopy and Hyperion imagery. J. Geochem. Explor. 2013, 132, 26-33. [CrossRef]

41. Zhang, T.; Li, L.; Zheng, B. Estimation of agricultural soil properties with imaging and laboratory spectroscopy. J. Appl. Remote Sens. 2013, 7, 73587. [CrossRef]

42. Castaldi, F.; Casa, R.; Castrignanò, A.; Pascucci, S.; Palombo, A.; Pignatti, S. Estimation of soil properties at the field scale from satellite data: A comparison between spatial and non-spatial techniques. Eur. J. Soil Sci. 2014, 65, 842-851. [CrossRef]

43. Jaber, S.M.; Lant, C.L.; Al-Qinna, M.I. Estimating spatial variations in soil organic carbon using satellite hyperspectral data and map algebra. Int. J. Remote Sens. 2011, 32, 5077-5103. [CrossRef]

44. Dalal, R.C.; Henry, R.J. Simultaneous determination of moisture, organic carbon, and total nitrogen by near infrared reflectance spectrophotometry. Soil Sci. Soc. Am. J. 1986, 50, 120-123. [CrossRef]

45. Vasques, G.M.; Grunwald, S.; Sickman, J.O. Comparison of multivariate methods for inferential modeling of soil carbon using visible/near-infrared spectra. Geoderma 2008, 146, 14-25. [CrossRef]

46. Chang, C.W.; Laird, D.A.; Mausbach, M.J.; Hurburgh, C.R. Near-infrared reflectance spectroscopy-principal components regression analyses of soil properties. Soil Sci. Soc. Am. J. 2001, 65, 480-490. [CrossRef]

47. Islam, K.; Singh, B.; McBratney, A. Simultaneous estimation of several soil properties by ultra-violet, visible, and near-infrared reflectance spectroscopy. Aust. J. Soil Res. 2003, 41, 1101-1114. [CrossRef]

48. Vasques, G.M.; Grunwald, S.; Sickman, J.O. Modeling of soil organic carbon fractions using visible-near-infrared spectroscopy. Soil Sci. Soc. Am. J. 2009, 73, 176-184. [CrossRef]

49. Viscarra Rossel, R.A.; Behrens, T. Using data mining to model and interpret soil diffuse reflectance spectra. Geoderma 2010, 158, 46-54. [CrossRef]

50. Li, D.; Chen, X.Z.; Peng, Z.P.; Chen, S.S.; Chen, W.Q.; Han, L.S.; Li, Y.J. Prediction of soil organic matter content in a litchi orchard of South China using spectral indices. Soil Tillage Res. 2012, 123, 78-86. [CrossRef]

51. Bartholomeus, H.M.; Schaepman, M.E.; Kooistra, L.; Stevens, A.; Hoogmoed, W.B.; Spaargaren, O.S.P. Spectral reflectance based indices for soil organic carbon quantification. Geoderma 2008, 145, 28-36. [CrossRef] 
52. FAO. World Reference Base for Soil Resources 2014; World Soil Resources Report 106; Food and Agriculture Organization: Rome, Italy, 2014.

53. Álvarez, M.A.; Marquínez, J. Impacto de los Incendios Forestales en Asturias. Análisis de los Últimos 30 años; KRK Ediciones: Oviedo, Spain, 2007.

54. Fernández, S.; Marquínez, J.; Duarte, R.M. A susceptibility model for post wildfire soil erosion in a temperate oceanic mountain area of Spain. Catena 2005, 61, 256-272. [CrossRef]

55. Díaz, T.E.; Fernández, J.A. El paisaje vegetal de Asturias: Guía de la excursión. Itinera Geobot. 1994, 8, 5-242.

56. Recondo, C.; Wozniak, E.; Pérez-Morandeira, C.S. Map of Burnt Zones in Asturias in the Period 1991-2001 created from Landsat-TM Images. In Proceedings of the 4th Workshop on Remote Sensing and GIS Applications to Forest Fires Management, Ghent, Belgium, 5-7 June 2003; Chuvieco, E., Martín, P., Justice, C., Eds.; 2003; pp. 193-196.

57. Schlapfer, D.; Richter, R. Geo-atmospheric processing of airborne imaging spectrometry data. Part 1: Parametric orthorectification. Int. J. Remote Sens. 2002, 23, 2609-2630. [CrossRef]

58. Richter, R.; Schlapfer, D. Geo-atmospheric processing of airborne imaging spectrometry data. Part 2: Atmospheric/topographic correction. Int. J. Remote Sens. 2002, 23, 2631-2649. [CrossRef]

59. Richards, J.A. Remote Sensing Digital Image Analysis, 5th ed.; Springer: Berlin, Germany, 2013; p. 494.

60. Pearlman, J.S.; Barry, P.S.; Segal, C.C.; Shepanski, J.; Beiso, D.; Carman, S.L. Hyperion, a space-based imaging spectrometer. IEEE Trans. Geosci. Remote Sens. 2003, 41, 1160-1173. [CrossRef]

61. Datt, B.; McVicar, T.R.; Van Niel, T.G.; Jupp, D.L.B.; Pearlman, J.S. Preprocessing EO-1 Hyperion hyperspectral data to support the application of agricultural indexes. IEEE Trans. Geosci. Remote Sens. 2003, 41, 1246-1259. [CrossRef]

62. Jackson, R.D.; Huete, A.R. Interpreting vegetation indices. Prev. Vet. Med. 1991, 11, 185-200. [CrossRef]

63. Rouse, J.W.; Haas, R.H.; Schell, J.A.; Deering, D.W. Monitoring Vegetation Systems in the Great Plains with ERTS. In Proceedings of the 3rd Earth Resource Technology Satellite (ERTS) Symposium, Washington, DC, USA, 10-14 December 1973; pp. 309-317.

64. Ben-Dor, E.; Inbar, Y.; Chen, Y. The reflectance spectra of organic matter in the visible near-infrared and short wave infrared region (400-2500 nm) during a controlled decomposition process. Remote Sens. Environ. 1997, 61, 1-15. [CrossRef]

65. Beyer, L.; Kahle, P.; Kretschmer, H.; Wu, Q. Soil organic matter composition of man-impacted urban sites in North Germany. J. Plant Nutr. Soil Sci. 2001, 164, 359-364. [CrossRef]

66. Yu, X.; Liu, Q.; Wang, Y.B.; Liu, X.Y.; Liu, X. Evaluation of MLSR and PLSR for estimating soil element contents using visible/near-infrared spectroscopy in apple orchards on the Jiaodong peninsula. Catena 2016, 137, 340-349. [CrossRef]

67. Venables, W.N.; Ripley, B.D. Modern Applied Statistics with S, 4th ed.; Springer: New York, NY, USA, 2002.

68. Wold, S.; Sjöström, M.; Eriksson, L. PLS-regression: A basic tool of chemometrics. Chemom. Intell. Lab. 2001, 58, 109-130. [CrossRef]

69. Haaland, D.M.; Thomas, E.V. Partial least-squares methods for spectral analyses. 1. Relation to other quantitative calibration methods and the extraction of qualitative information. Anal. Chem. 1988, 60, 1193-1202. [CrossRef]

70. Akaike, H. Fitting autoregressive models for prediction. Ann. Inst. Stat. Math. 1969, 21, 243-247. [CrossRef]

71. Li, B.; Morris, J.; Martin, E.B. Model selection for partial least squares regression. Chemom. Intell. Lab. 2002, 64, 79-89. [CrossRef]

72. Viscarra Rossel, R.A.; Jeon, Y.S.; Odeh, I.O.A.; McBratney, A.B. Using a legacy soil sample to develop a mid-IR spectral library. Soil Res. 2008, 46,1-16. [CrossRef]

73. Chong, I.G.; Jun, C.H. Performance of some variable selection methods when multicollinearity is present. Chemom. Intell. Lab. 2005, 78, 103-112. [CrossRef]

74. Chang, C.W.; Laird, D.A. Near-infrared reflectance spectroscopic analysis of soil C and N. Soil Sci. 2002, 167, 110-116. [CrossRef]

75. Hammersley, J.M.; Handscomb, D.C. Monte Carlo Methods; Chapman and Hall: London, UK, 1979.

76. Metropolis, N.; Ulam, S. The Monte Carlo method. J. Am. Stat. Assoc. 1949, 44, 335-341. [CrossRef] [PubMed]

77. Shapiro, S.S.; Wilk, M.B. An analysis of variance test for normality (complete samples). Biometrika 1965, 52, 591-611. [CrossRef] 
78. Santín, C.; Knicker, H.; Fernández, S.; Menéndez-Duarte, R.; Álvarez, M.A. Wildfires influence on soil organic matter in an Atlantic mountainous region (NW of Spain). Catena 2008, 74, 286-295. [CrossRef]

79. Menéndez Duarte, R.; Wozniak, E.; Recondo, C.; Cabo, C.; Marquínez, J.; Fernández, S. Estimation of surface roughness and stone cover in burnt soils using SAR images. Catena 2008, 74, 264-272. [CrossRef]

80. Stoner, E.R.; Baumgardner, M.F. Characteristic variations in reflectance of surface soils. Soil Sci. Soc. Am. J. 1981, 45, 1161-1165. [CrossRef]

81. Schulze, D.G.; Nagel, J.L.; Van Scoyoc, G.E.; Henderson, T.L.; Baumgardner, M.F.; Scott, D.E. Significance of organic matter in determining soil colors. In Soil Color; Bigham, J.M., Ciolkosz, E.J., Eds.; Soil Science Society of America: Madison, WI, USA, 1993; pp. 71-90.

82. Vinogradov, B.V. Remote sensing of the humus content of soils. Sov. Soil Sci. 1981, 11, 114-123.

83. Hummel, J.W.; Sudduth, K.A.; Hollinger, S.E. Soil moisture and organic matter prediction of surface and subsurface soils using an NIR soil sensor. Comput. Electron. Agric. 2001, 32, 149-165. [CrossRef]

84. Henderson, T.L.; Baumgardner, M.F.; Franzmeier, D.P.; Stott, D.E.; Coster, D.C. High dimensional reflectance analysis of soil organic matter. Soil Sci. Soc. Am. J. 1992, 56, 865-872. [CrossRef]

85. Gitelson, A.A.; Merzlyak, M.N.; Lichtenthaler, H.K. Detection of red edge position and chlorophyll content by reflectance measurements near $700 \mathrm{~nm}$. J. Plant Physiol. 1996, 148, 501-508. [CrossRef]

86. Huang, A.; Li, G.; Fu, F.; Fei, B. Use of visible and near infrared spectroscopy to predict klason lignin content of bamboo, Chinese fir, Paulownia, and Poplar. J. Wood Chem. Technol. 2008, 28, 194-206. [CrossRef]

87. Kooistra, L.; Wanders, J.; Epema, G.F.; Leuven, R.S.E.W.; Wehrens, R.; Buydens, L.M.C. The potential of field spectroscopy for the assessment of sediment properties in river floodplains. Anal. Chim. Acta 2003, 484, 189-200. [CrossRef]

88. De Gryze, S.; Six, J.; Bossuyt, H.; Van Oost, K.; Merckx, R. The relationship between landform and the distribution of soil C, N and P under conventional and minimum tillage. Geoderma 2008, 144, 180-188. [CrossRef]

89. Gomez, C.; Gholizadeh, A.; Borůvka, L.; Lagacherie, P. Using legacy data for correction of soil surface clay content predicted from VNIR/SWIR hyperspectral airborne images. Geoderma 2016, 276, 84-92. [CrossRef]

90. Tanii, J.; Ito, Y.; Iwasaki, A. Instrument development status and performances of hyperspectral imager suite (HISUI) - Onboard data correction. In Proceedings of the 2014 IEEE Geoscience and Remote Sensing Symposium, Quebec City, QC, Canada, 13-18 July 2014; pp. 2007-2010.

91. Meini, M.; Fossati, E.; Giunti, L.; Molina, M.; Formaro, R.; Longo, F.; Varacalli, G. The PRISMA mission hyperspectral payload. In Proceedings of the 66th International Astronautical Congress (IAC 2015), Jerusalem, Israel, 12-16 October 2015; p. 30270.

92. Guanter, L.; Kaufmann, H.; Segl, K.; Foerster, S.; Rogass, C.; Chabrillat, S.; Kuester, T.; Hollstein, A.; Rossner, G.; Chlebek, C.; et al. The EnMAP spaceborne imaging spectroscopy mission for Earth observation. Remote Sens. 2015, 7, 8830-8857. [CrossRef]

93. Michel, S.; Gamet, P.; Lefevre-Fonollosa, M.J. HYPXIM-A hyperspectral satellite defined for science, security and defence users. In Proceedings of the 3rd Workshop on Hyperspectral Image and Signal Processing: Evolution in Remote Sensing (WHISPERS), Lisbon, Portugal, 6-9 June 2011; pp. 1-4.

94. Sagi, E. SHALOM-Spaceborne Hyperspectral Applciative Land and Ocean Mission. In Proceedings of the 66th International Astronautical Congress (IAC 2015), Jerusalem, Israel, 12-16 October 2015; p. 31056.

95. Lee, C.M.; Cable, M.L.; Hook, S.J.; Green, R.O.; Ustin, S.L.; Mandl, D.J.; Middleton, E.M. An introduction to the NASA Hyperspectral InfraRed Imager (HyspIRI) mission and preparatory activities. Remote Sens. Environ. 2015, 167, 6-19. [CrossRef]

96. Castaldi, F.; Palombo, A.; Santini, F.; Pascucci, S.; Pignatti, S.; Casa, R. Evaluation of the potential of the current and forthcoming multispectral and hyperspectral imagers to estimate soil texture and organic carbon. Remote Sens. Environ. 2016, 179, 54-65. [CrossRef]

(C) 2017 by the authors. Licensee MDPI, Basel, Switzerland. This article is an open access article distributed under the terms and conditions of the Creative Commons Attribution (CC BY) license (http:/ / creativecommons.org/licenses/by/4.0/). 